\title{
دراسة تحليلية للهيكل السلعى للتجارة الخارجية المصرية وكفاعتها مع دول حوض النيل
}

\author{
ياسر عبد الحميا عبد الراضى وعيد \\ أستاذ الاقتصاد الزراعى وعميد كلية الزراعة والموارد الطبيعية- جامعة أسوان الريد \\ حسين حسن على أدم \\ أستاذ الاقتصاد الزراعى المساعد بكلية الزراعة عل أدم \\ جامعة أسوان \\ يوسف محمد عبد المحسن سالم فرحان \\ طالب دكتوراة بمعهد البحوث والداريدات الافريقية \\ جامعة أسوان
}




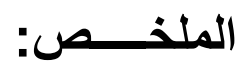

تكمن المشكلة البحثية في انخفاض حجم التبادل التجاري بين مصر ودول حوض النيل سواء الصادرات المصرية او الواردات المصرية منها، ومن ثم يلزم دراسة

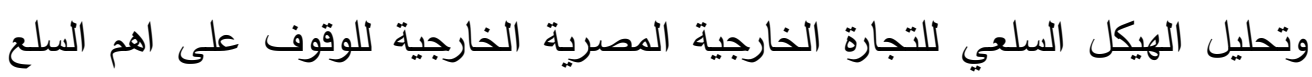

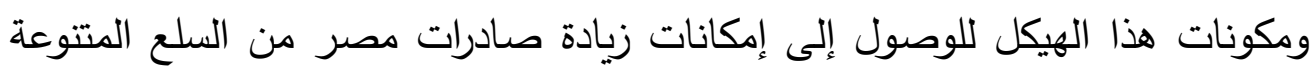

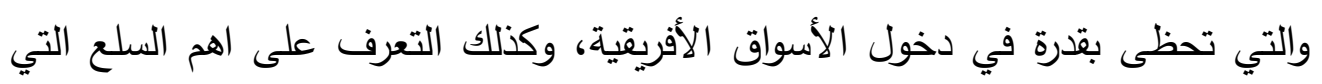

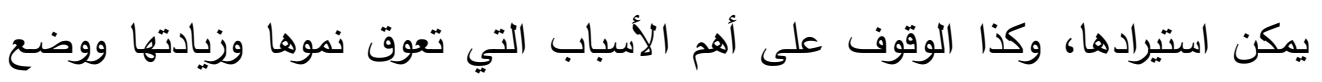

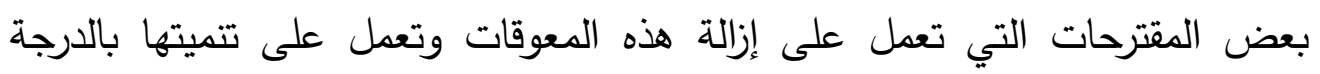
المأمولة، ويستهاف البحث بصفة رئيسية تحليل ودراسة الهيكل السلعى للتهل التجارة

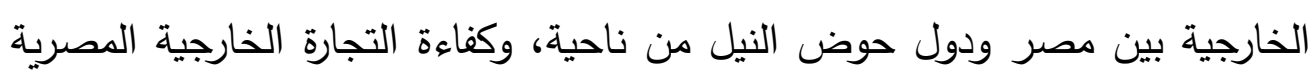

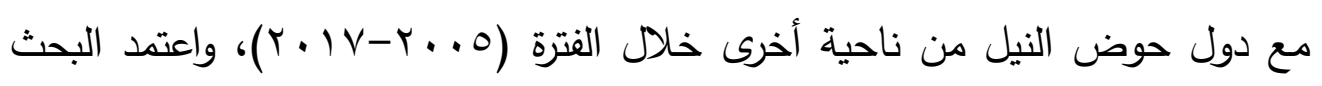
بصفة أساسية على الاساليب الوصفية والكمية، وعلى وجه التحديد التحاديد تم استخدام

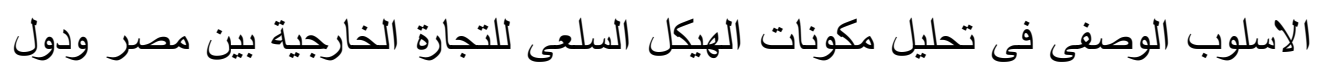
حوض النيل والتعرف على أهم مكوناته من ناحية، وتقدير كفاءة التجارة الخارجية الكلية لإنيل

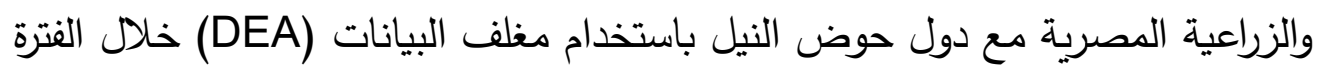

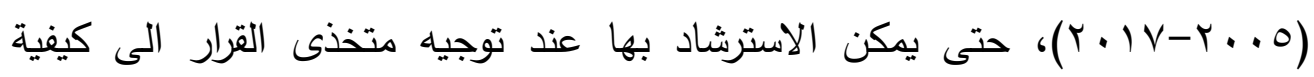

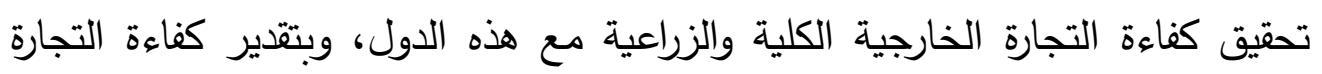

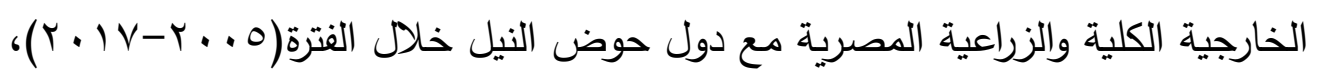

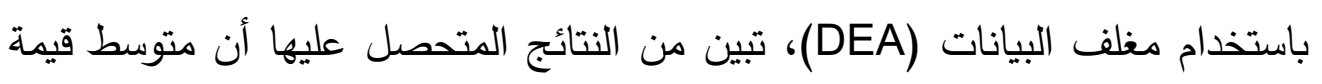

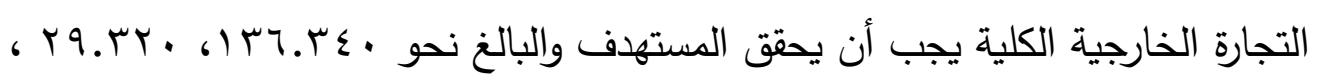

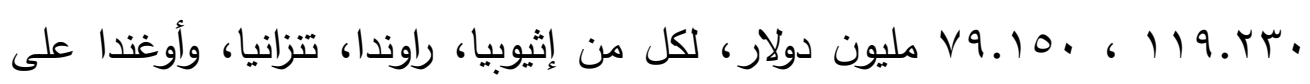

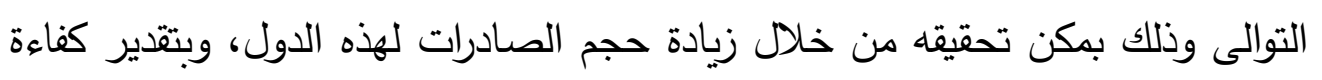

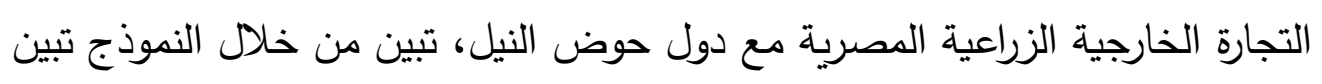

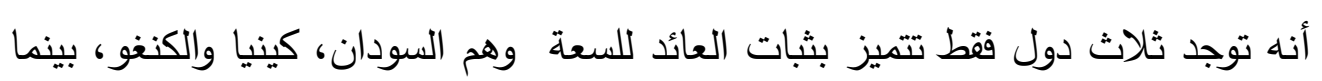

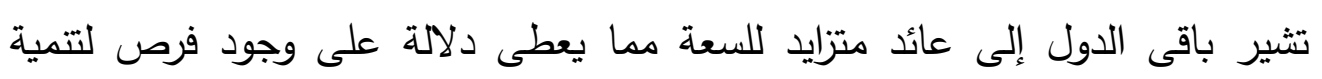


التجارة الخارجية الكلية الدصرية إلى تلك الدول، وتثير النتائج إلى أن متوسط قيمة

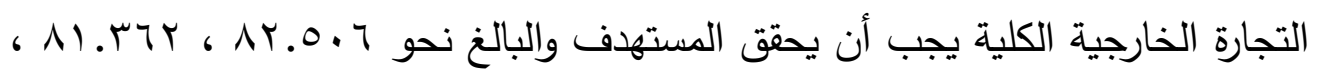

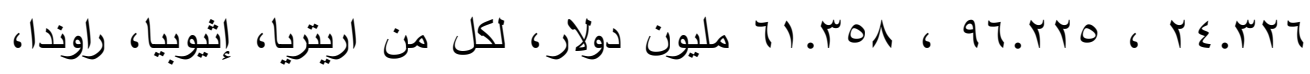

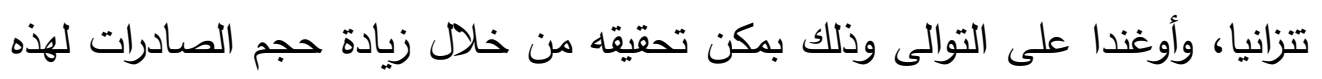

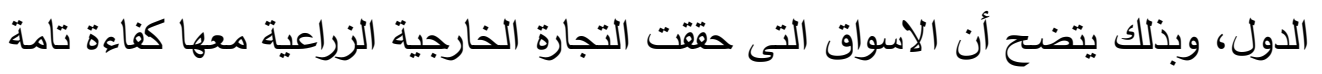

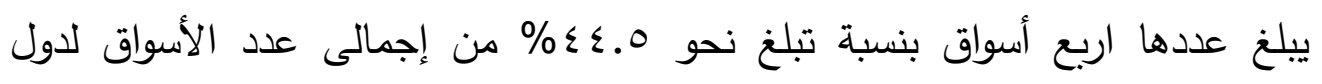
حوض النيل، فى حين بلغ عدد الأسواق التى لم تحقق التجارة الخارجية الزراعية معها كأها

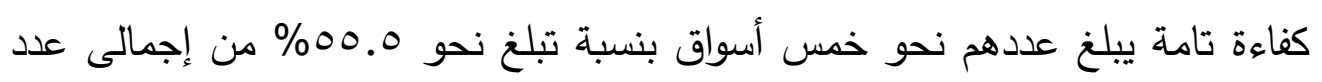

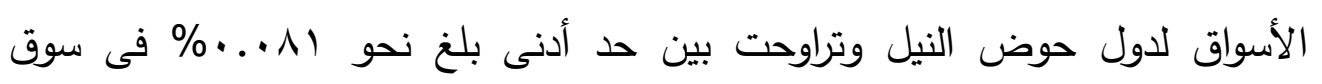

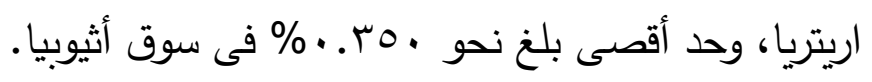

\section{وفى ضوء ما سبق يوصى البحث بما يلى:}

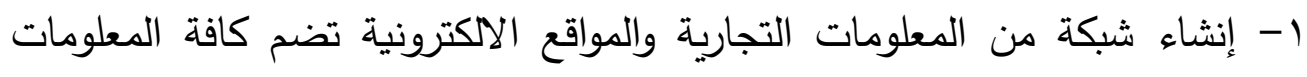

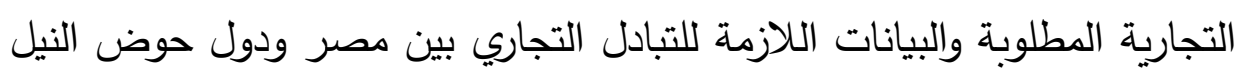

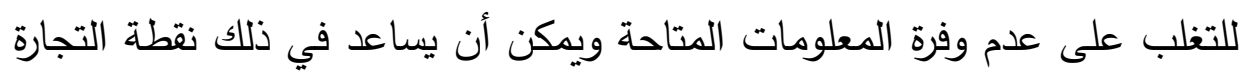
الدولية المصرية> r- تغعيل دور شركة ضمان الصادرات في تغطية المخاطر التي تواجه الصادرات

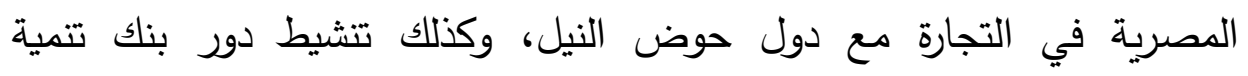
الصادرات في توفير التمويل اللازم للصادرات المصرية الي دول حوض في التصن النيل.

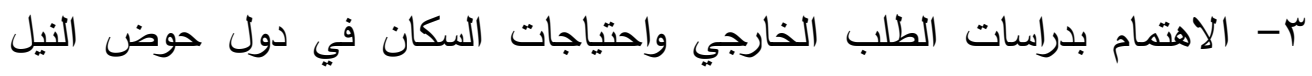
والعوامل المؤثرة على زيادة الصادرات المصرية، ونشر هذه المعلومات المات لتكات التكون دليلا للمصدرين والمنتجين، علاوة على إقامة المعارض الترويجية للمنتجات المصرية المرادية في أهم أسواق دول حوض النيل. ع- إنشاء إدارة مصرية متخصصة في التعامل مع أسواق دول حوض النيل لقياس

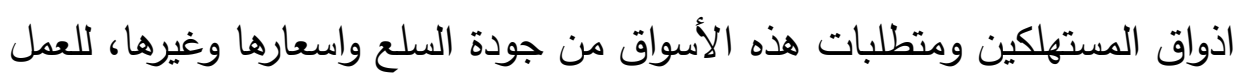
على تتشيط الصادرات المصرية الى دول حوض النيل. 


\title{
الكلمات المفتاحية: الهيكل السلعى - التجارة الخارجية - دول حوض النيل.
}

\section{An Analytical Study of the Commodity Structure of Egyptian Foreign Trade and its Efficiency with the Nile Basin Countries}

\begin{abstract}
:
The research problem lies in the low volume of trade exchange between Egypt and the Nile Basin countries, whether Egyptian exports or Egyptian imports from them, and then it is necessary to study and analyze the commodity structure of the Egyptian foreign foreign trade in order to find out the most important commodities and components of this structure to reach the potential for increasing Egypt's exports of the various commodities that are With an ability to enter the African markets, as well as to identify the most important commodities that can be imported, as well as to identify the most important reasons that impede their growth and increase and to develop some proposals that work to remove these obstacles and develop them to the desired degree, the research aims mainly to analyze and study the commodity structure of foreign trade between Egypt and the Nile Basin countries on the one hand, and the efficiency of Egyptian foreign trade with the Nile Basin countries on the other hand during the period (2005-2017), and the research relied mainly on descriptive and quantitative methods, and in particular the descriptive method was used in analyzing the components of the commodity structure of foreign trade between Egypt and the Nile Basin countries, identifying the most important components of it, and assessing the efficiency of the Egyptian total and agricultural foreign trade with the Nile Basin countries using Mughal P-Data (DEA) during the period (2005-2017), so that
\end{abstract}


ياسر عبد الر اضي وآخرن، دراسة تحليلية للهيكل السلعى للتجارة الخارجية المصرية...

it can be used when guiding decision-makers on how to achieve the efficiency of total and agricultural foreign trade with these countries

\section{The research recommends the following:}

1-Establishing a network of commercial information and electronic sites that includes all the required commercial information and data necessary for trade exchange between Egypt and the Nile Basin countries to overcome the lack of available information and the Egyptian international trade point can help in this.

2- Activating the role of the Export Guarantee Company in covering the risks facing Egyptian exports in trade with the Nile Basin countries, as well as activating the role of the Export Development Bank in providing the necessary financing for Egyptian exports to the Nile Basin countries.

3- Attention to studies of external demand and the needs of the population in the Nile Basin countries and the factors affecting the increase in Egyptian exports, and the publication of this information to be a guide for exporters and producers, in addition to holding promotional exhibitions of Egyptian products in the most important markets of the Nile Basin countries.

4- Establishing an Egyptian administration specialized in dealing with the markets of the Nile Basin countries to measure the tastes of consumers and the requirements of these markets in terms of the quality of goods and their prices and others, to work to stimulate Egyptian exports to the Nile Basin countries. 


\section{مقدمة:}

يمثل قطاع التجارة الخارجية مكانة متميزة في الاقتصاد المصري لأهميته في

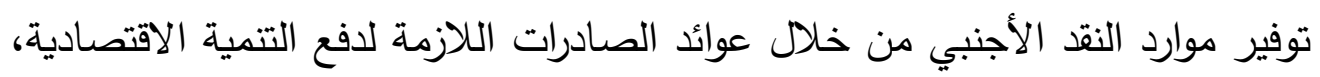
كما تعتبر التجارة الخارجية واحدة من أهم مرتكزات التتمية الاقتصادية فمن خلالها

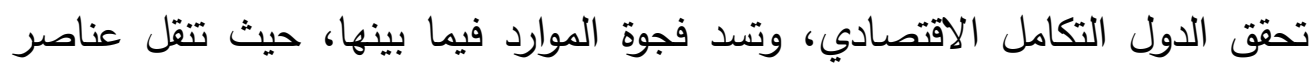
الإنتاج من سلع وخدمات من الدول التي تتمتع بوفرة نسبية من هذه العناصر تصدير

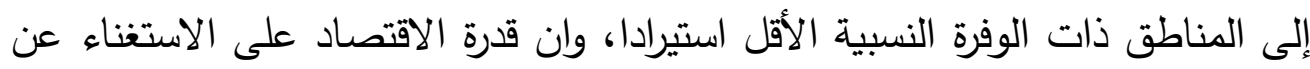

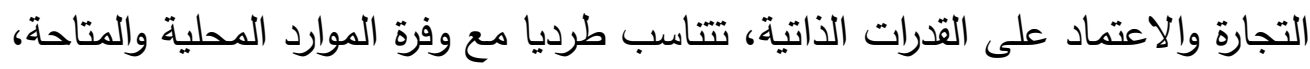

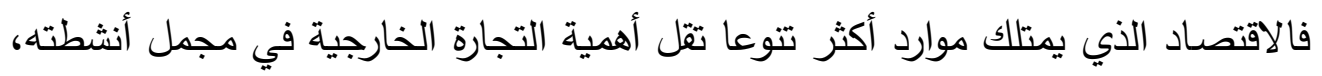

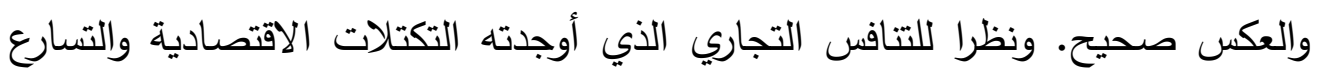

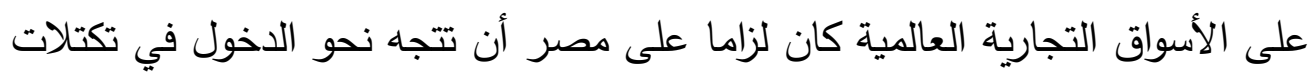
إقليمية كخطوة ضرورية على طريق تتمية وتعظيم التكامل بين هذه التكتلات (r)، ولقد

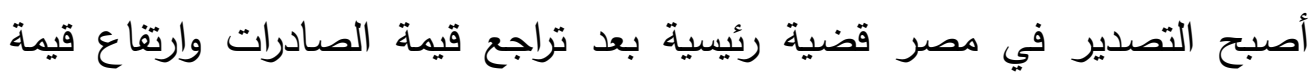
الواردات، وما صاحب ذلك من تزايد للعجز في الميزان التجاري وانخفاض في قيمة

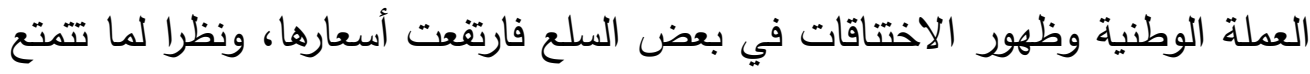
به مصر من ميزة نسبية مرتفعة في عديد من السلع خاصة السلع الزراعية مقارنة

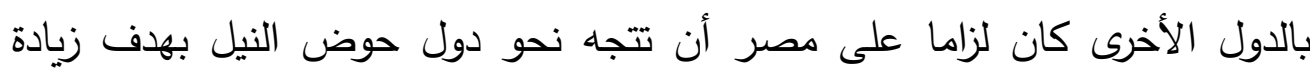
الصادرات ومن ثم زيادة الدخل القومي وتحسين مستوى معيشة المواطن المصري، المئه بالإضافة الى اعتماد مصر على سد بعض احتياجاتها من السلع اللازمة لبرامج التتمية

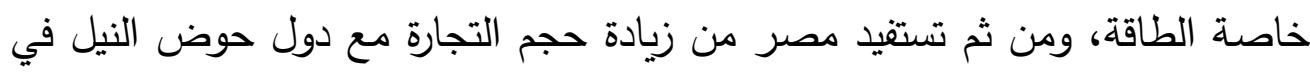
ظل الاتفاقيات المشتركة بينها وبين هذه الدول، ونظرا للتنافس التجاري الذي اوجدئه دئه دونه

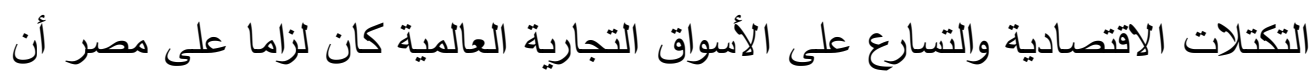

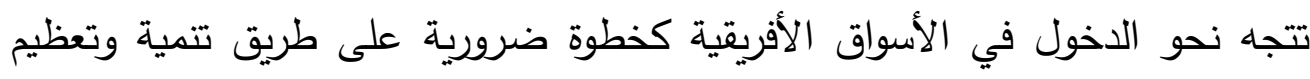
التبادل التجاري مع دول القارة، ومن ذلك المنطلق انضمت مصر إلى التى التكتل

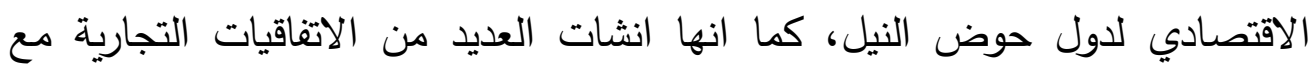


الكثير من دول القارة للاستفادة من فرص التصدير اليها وايضا تحقيق مكاسب من استيراد المواد والسلع التي تتميز بها دول افريقيا نسبيا عن غيرها في دول العالم. المشكلة البحثية:

لقد اتجهت مصر في السنوات الأخيرة نحو ابرام العديد من الاتفاقيات التجارية

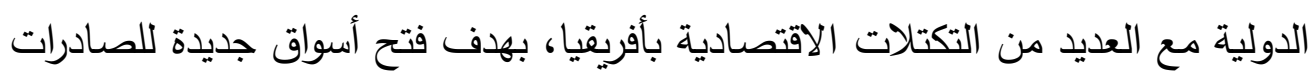
المصرية فضلا عن إمكانية تنويع مثل هذه الصادرات الامر الذي من شأنه أن يؤدي بـاتي إلى زيادة حصيلة الصادرات وتحسين وضع ميزان المدفوعات، وكذلك زيادة التبادل التجاري من خلال حصول مصر على ما تحتاجه من سلع من هذه الدول وبأسعار تقل عن نظيرتها العالمية، ورغم كل ذلك فان المتتبع لحركة التجارة الخارجية المصرية مناهية الافريقية يلمس تضاؤلها وانخفاضها دون المأمول من هذه العلاقات، وتكمن المشكلة البحثية في انخفاض حجم التبادل التجاري بين مصر ودول حوض النيل سواء الصادرات المصرية او الواردات المصرية منها، ومن ثم يلزم دراسة وتحليل الهيكل السلعي للتجارة الخارجية المصرية الخارجية للوقوف على اهم السلع ومكونات هذا الهيكل للوصول إلى إمكانات زيادة صادرات مصر من السلع المتنوعة والتي تحظى بقدرة في دخول الأسواق الأفريقية، وكذلك التعرف على الهم السلع التي يمكن استيرادها، وكذا الوقوف على أهم الأسباب التي تعوق نموها وزيادتها ووضع بعض المقترحات التي تعمل على إزالة هذه المعوقات وتعمل على تتميتها بالارجة المأمولة.

\section{الأهداف البحثية:}

يستهدف البحث بصفة رئيسية تحليل ودراسة الهيكل السلعى للتجارة الخارجية بين مصر ودول حوض النيل من ناحية، وكفاءة التجارة الخارجية المصرية مع دول

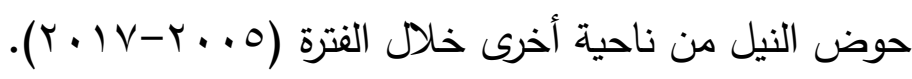




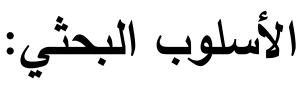

اعتمد البحث بصفة أساسية على الاساليب الوصفية والكمية، وعلى وجه التحديد تم استخدام الاسلوب الوصفى فى تحليل مكونات الهيكل السلعى للتجارة الخارجية بين مصر ودول حوض النيل والتعرف على أهم مكوناته من ناحية، وتقدير

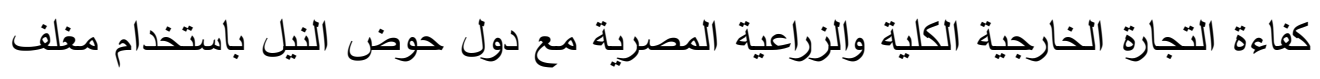

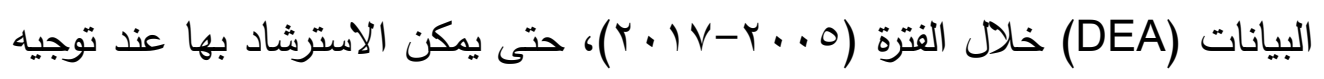
متخذى القرار الى كيفية تحقيق كفاءة التجارة الخارجية الكلية والزراعية مع هذه الدول.

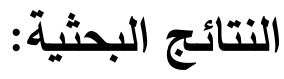

أولاً: تطور هيكل الصادرات الكلية المصرية لدول حوض النيل:

يتناول هذا الجزء كما هو موضتح بالجدول رقم (1)، دراسة وتحليل تطور هيكل الصادرات الكلية المصرية مع دول حوض النيل والذى يتمثل فى تسع مجموعات رئيسية احتلت مجموعة المنتجات الحيوانية والنباتية والمشروبات والتبغ المركز الأول حيث بلغ متوسط قيمة صادراتها الى دول حوض النيل خلال فترة الدراسة نحو 9.1. الصادرات الى هذه الدول، يليها مجموعة المنتجات الكيمياوية والبلاستيك، مجموعة لهونة المنتجات المعدنية، مجموعة المطاط والجلود والاخشاب والورق، مجموعة الالات والاجهزة الالية والكهربائية ومعدات النقل، مجموعة مصنوعات الرخام والاحجار

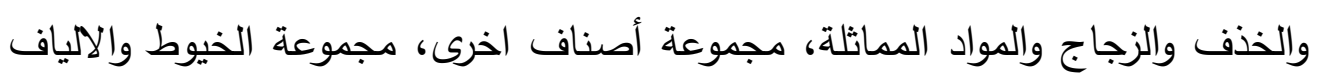
النسيجية ومنتجات الغزل والنسيج والملابس، ومجموعة الوقود والمنتجات البترولية

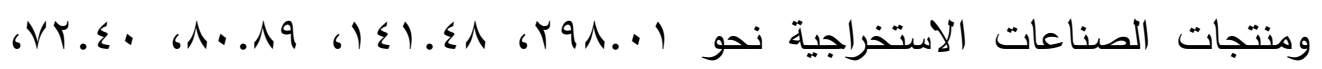

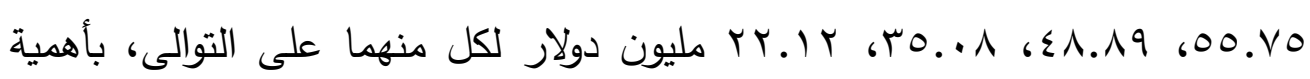

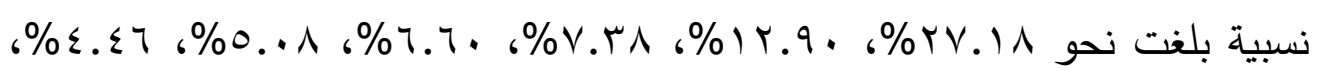




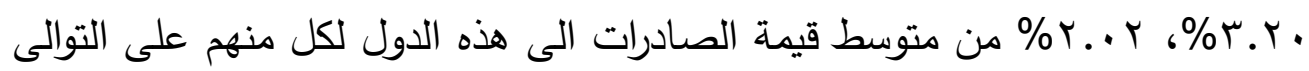
خلال فترة الدراسة.

جدول رقم (1): تطور هيكل الصادرات الكلية المصرية لدول حوض النيل خلا

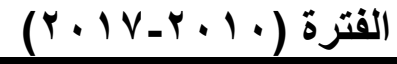

\begin{tabular}{|c|c|c|}
\hline$\%$ & المتوسط بالمليون دولار دولار & 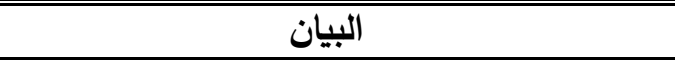 \\
\hline M & $r \leqslant 1.90$ & المنتجات الحيوانية والنباتية والمشروبات والتبغ \\
\hline rV.IA & หq^.. 1 & المنتجات الكيمياوية والبلاستيك \\
\hline Ir.q. & $1 \leq 1 . \leqslant \wedge$ & المنتجات المعدنية \\
\hline V.rA & $\wedge . . \wedge 9$ & المطاط والجلود والاخشاب والورق \\
\hline 7.7. & VY.E. & الالات والاجهزة الالية والكهربائية ومعدات النقل \\
\hline$\bullet . \wedge$ & $\bullet \bullet . \vee \bullet$ & ينوعات الرخام والاحجار والخذف والزجاج والمواد المماثلة \\
\hline$\varepsilon . \varepsilon\rceil$ & $\varepsilon \wedge . \wedge q$ & أصناف اخرى \\
\hline$r . r$. & ro.. & الخيوط والالياف النسيجية ومنتجات الغزل والنسيج والملابس \\
\hline$r . \cdot r$ & rr.Ir & الوقود والمنتجات البترولية ومنتجات الصناعات الاستخراجية \\
\hline $1 \cdots$ & 1.97 .07 & الاجمالى \\
\hline
\end{tabular}

المصـدر: الجهاز المركزى للتعبـة العامـة والاحصـاء، التبـادل التجـارى بـين مصـر ودول حـوض النيل، اعداد مختلقة ، 9 1. ب.

ثانيا: تطور هيكل الواردات الكلية المصرية لدول حوض النيل: تثير بيانات الجدول رقم (r)، دراسة تطور هيكل الواردات الكلية المصرية من دول حوض النيل وترتيبها تنازلياً وفقا لمساهمتها فى هيكل الواردات احتلت المنتجات الحيوانية والنباتية والمشروبات والتبغ المركز الأول حيث بلغ متوسط قيمة وارداتها من

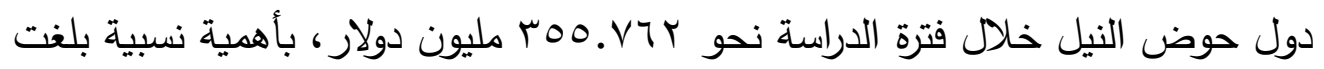

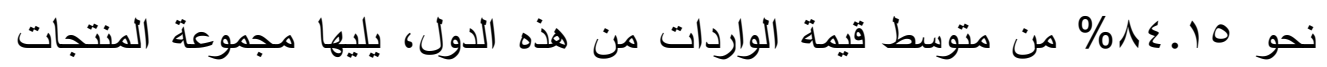
المعدنية، مجموعة الخيوط والالياف النسيجية ومنتجات الغزل والنسيج والملابس، مجموعة المطاط والجلود والاخشاب والورق، مجموعة المنتجات الكيمياوية والبلاستيك، مجموعة الالات والاجهزة الالية والكهربائية ومعدات النقل، أصناف أخرى، مجموعة مجاتهو

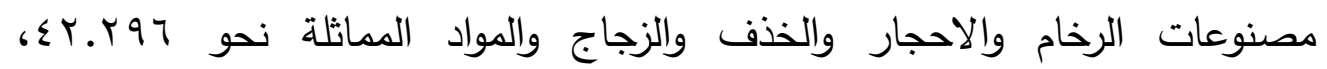

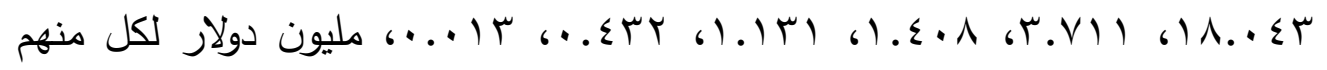




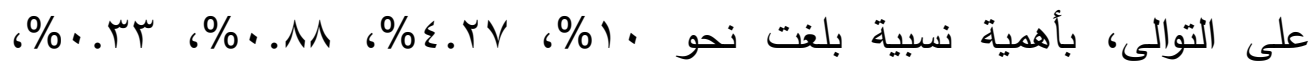
rV

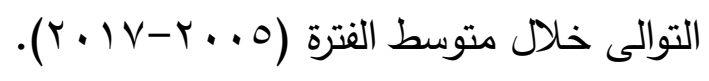

ثالثاً: تطور هيكل التجارة الخارجية الكلية المصرية لدول حوض اضون النيل: بدراسة تطور هيكل التجارة الخارجية الكلية المصرية مع دول حوض النيل، تثير بيانات الجدول رقم (r)، أن مجموعة المنتجات الحيوانية والنباتية والمشروبات والتبخ احتلت المركز الاول حيث بلغ متوسط قيمة التجارة الخارجية لدول حوض النيل

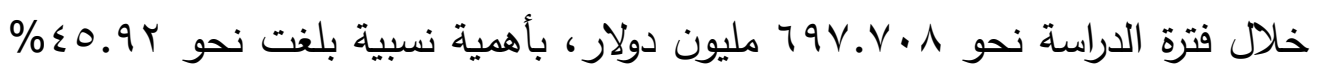
من متوسط قيمة الواردات من هذه الدول، يليها مجموعة المنتجات الكيمياوية

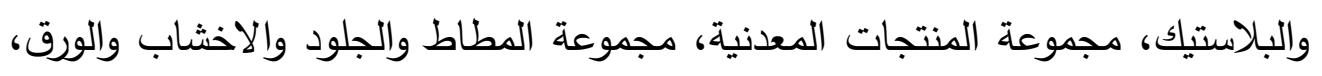
مجموعة الالات والاجهزة الالية والكهربائية ومعدات النقل، مجموعة المصنوعات الرخام والاحجار والخذف والزجاج والمواد المماثلة، مجموعة الخيوط والالياف النسيجية

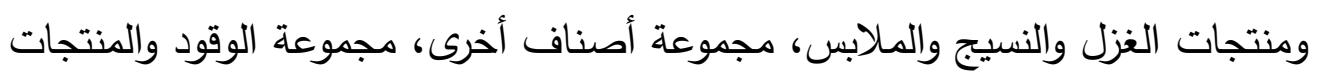

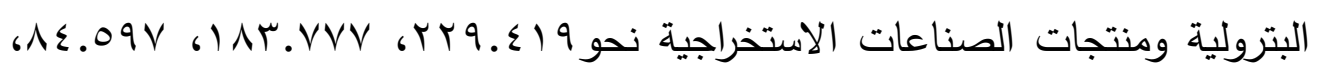

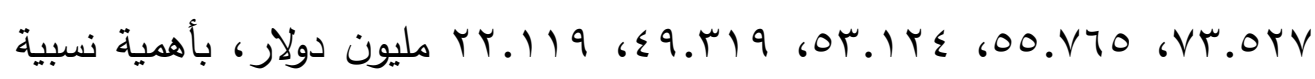

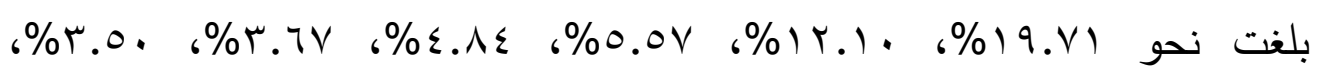

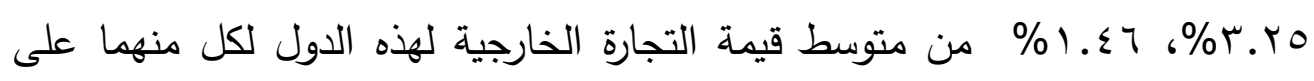
التوالى. جدول رقم (Y): تطور هيكل الواردات الكلية المصرية لدول حوض النيل خلال الفترة $(r+1 V-r+1 \cdot)$

\begin{tabular}{|c|c|c|}
\hline$\%$ & المتوبط بالمليون دولار & 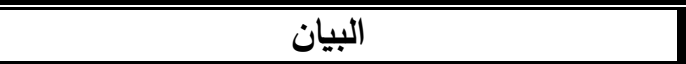 \\
\hline$\Lambda \leqslant .10$ & roo.v4r & المنتجات الحيوانية والنباتية والمشروبات والتبغ \\
\hline $1 \cdots$ & ६५.५१५ & المنتجات المعدنية \\
\hline \&.rV & $1 \wedge . \cdot \leq r$ & الخيوط والالياف النسيجية ومنتجات الغزل والنسيج والملابس \\
\hline$\cdot . \wedge \wedge$ & r.Vil & المطاط والجلود والاخشاب والورق \\
\hline.$r r$ & $1 . \varepsilon \cdot 1$ & المنتجات الكيمياوية والبلاستيك \\
\hline.$r V$ & $1.1 \% 1$ & الالات والاجهزة الالية والكهربائية ومعدات النقل \\
\hline
\end{tabular}


ياسر عبد الر اضي و آخرن، در اسة تحليلية للهيكل السلعى للتجارة الخارجية المصرية...

\begin{tabular}{|c|c|c|}
\hline .1 & 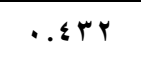 & أصناف اخرى \\
\hline$\cdots+1$ & $\cdots+1 r$ & مصنوعات الرخام والاحجار والخذف والزجاج والمواد المماثلة \\
\hline $1 \ldots$ & $\varepsilon r r . \vee q \neg$ & \\
\hline
\end{tabular}

المصدر: الجهاز المركزى للتعبة العامة والاحصاء، التبادل التجارى بين مصر ودول حوض النيل،

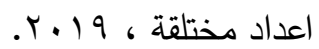

جدول رقم (r): تطور هيكل التجارة الخارجية الكلية المصرية لاول حوض النيل

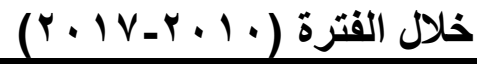

\begin{tabular}{|c|c|c|}
\hline$\%$ & المتوسط بالمليون دولار & 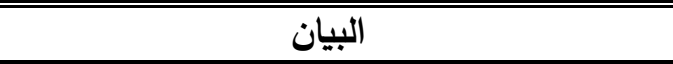 \\
\hline$\leqslant 0.9 r$ & $79 \vee \cdot \vee \cdot \Lambda$ & المنتجات الحيوانية والنباتية والمشروبات والتبغ \\
\hline $19 . v 1$ & Y99.\$19 & المنتجات الكيمياوية والبلاستيك \\
\hline Ir.l. & IAr.VVV & 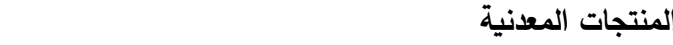 \\
\hline $0.0 \mathrm{~V}$ & $\wedge \varepsilon .09 \mathrm{~V}$ & ل لمطاط والجلود والاخشاب والورق \\
\hline$\varepsilon . \wedge \varepsilon$ & VT.OYV & الالات والاجهزة الالية والكهربائية ومعدات النقل \\
\hline r.TV & $00 . \vee 40$ & مصنوعات الرخام والاحجار والخذف والزجاج والمواد المماثلة \\
\hline r.०. & Or.lY & الخيوط والالياف النسيجية ومنتجات الغزل والنسيج والملابس \\
\hline T.Yo & $\{9.419$ & صناف اخرى \\
\hline $1 . \leqslant 7$ & rY.119 & لوقود والمنتجات البترولية ومنتجات الصناعات الاستخراجية \\
\hline $1 \cdots$ & 1019.ro & 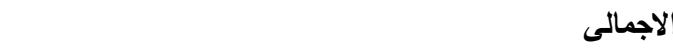 \\
\hline
\end{tabular}

المصدر: الجهاز المركزى للتعبة العامة والاحصاء، التبادل التجارى بين مصر ودول حوض النيل،

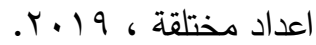

رابعاً: التوزيع الجغرافى للتجارة الخارجية الكلية والزراعية مع دول حوض النيل: يتناول هذا الجزء دراسة التوزيع الجغرافى للتجارة الخارجية الكلية المصرية مع دول حوض النيل للوقوف على أهم الاسواق فى التجارة المصرية مع تلك الدول خلال

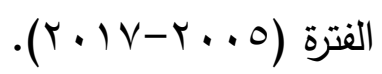

1- التوزيع الجغرافى لقيمة الصادرات المصرية الكلية الى دول حوض النيل: تثير بيانات الجدول رقم (ع)، دراسة التوزيع الجغرافى لقيمة الصادرات

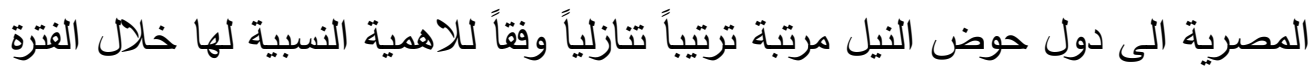

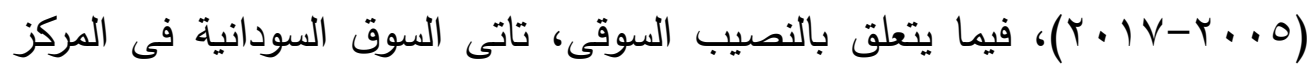


الاول، حيث بلغ متوسط قيمة الصادرات لتلك السوق خلال فترة الدراسة نحو

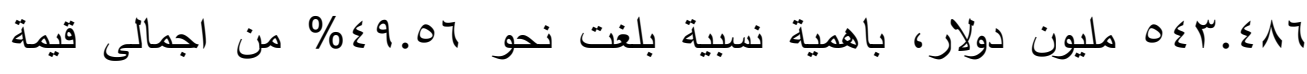

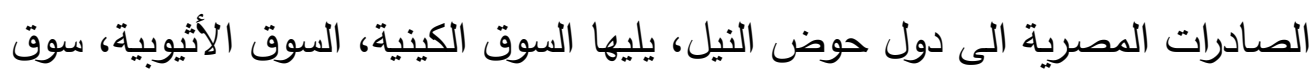

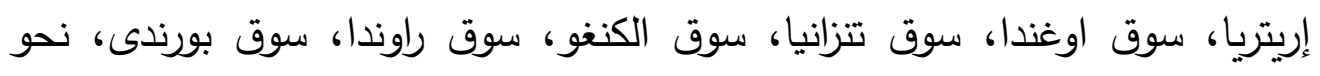

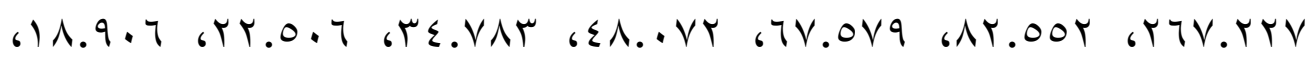
\% \% Y Y.YV

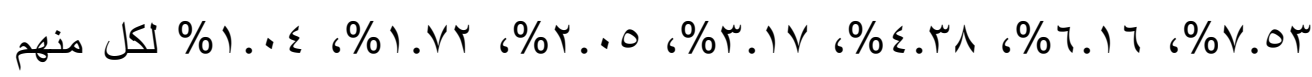
على التوالى من اجمالى قيمة الصادرات المصرية الى دول حوض النيل خلال فترة الدراسة.

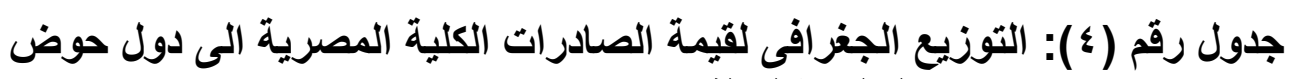

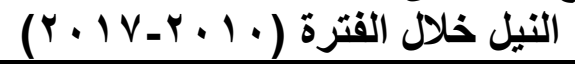

\begin{tabular}{|c|c|c|}
\hline$\%$ & المتوسط بالمليون دولار & الدولة \\
\hline$\$ 9.04$ & $0 \leqslant \Psi . \leqslant \wedge \uparrow$ & السودان \\
\hline$r \leq . r V$ & YTV.YTV & كينيا \\
\hline v.or & Ar.oor & أثيوبيا \\
\hline 8.17 & IV.OV9 & اريتريا \\
\hline \&.rA & $\varepsilon \Lambda . \cdot \vee r$ & |اوغندا \\
\hline r.IV & 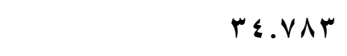 & تنزانيا \\
\hline r..o & r..0.T & الكنغو \\
\hline 1.Vr & 11.9 .9 & راوندا \\
\hline $1 . .2$ & $11 . \leqslant \leqslant v$ & بورندى \\
\hline $1 \ldots$ & 1.97 .009 & الاجمالى \\
\hline
\end{tabular}

المصدر: الجهاز المركزى للتعبة العامة والاحصاء، التبادل التجارى بين مصر ودول حوض النيل،

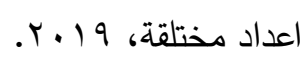

r - التوزيع الجغرافى لقيمة الواردات المصرية الكلية الى دول حوض النيل: تشير بيانات الجدول رقم (0) الى دراسة التوزيع الجغرافى لقيمة الواردات

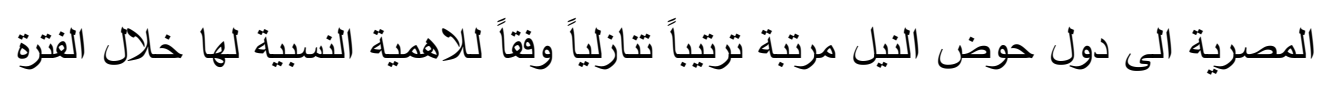




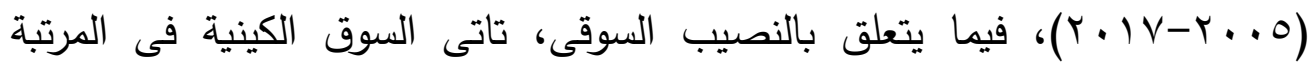
الاولى، حيث بلغ متوسط قيمة الواردات من تلك السوق خلال فترة الدراسة نحو

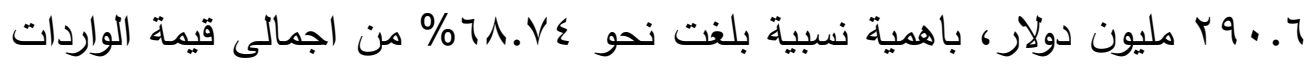

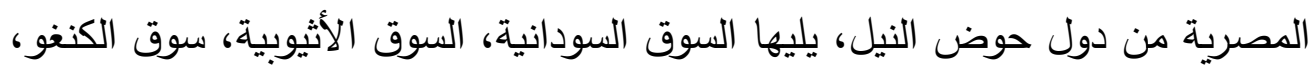
سوق اريتريا، سوق تنزانيا، سوق اوغندا، سوق راوندا، سوق بورندى، حيث بلغ نحو

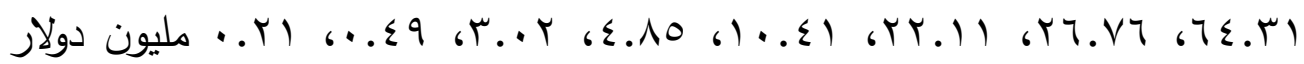
لكل منهم على التوالى من متوسط قيمة الواردات من تلك السوق خلال فترة الدراسة،

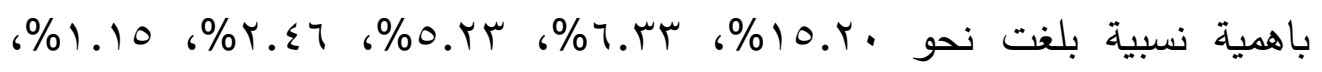

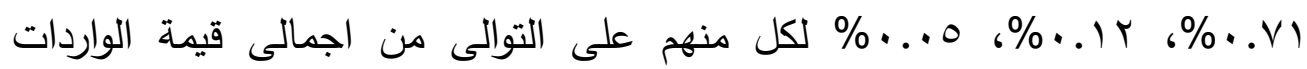

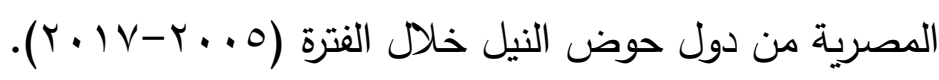

جدول رقم (•): التوزيع الجغرافى لقيمة الواردات الكلية المصرية الى دول حوض

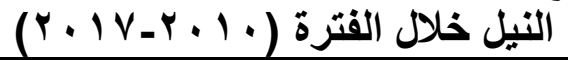

\begin{tabular}{|c|c|c|}
\hline$\%$ & المتوسط بالمليون دولار & الدولة \\
\hline 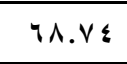 & $r 9 . .7$ & كينيا \\
\hline 10.41 & $T \leq . r 1$ & السودان \\
\hline r.r. & ד. & أثيوبيا \\
\hline $0 . r T$ & rY.ll & الكنغو \\
\hline r. & $1 \ldots \leqslant 1$ & اريتريا \\
\hline 1.10 & \&.^o & تنزانيا \\
\hline..$v 1$ & r...r & اوغذا \\
\hline. $.1 r$ &. .29 & راوندا \\
\hline$\ldots 0$ & $. r+$ & بورندى \\
\hline $1 \ldots$ & EYY.VT & | الاجمالى \\
\hline
\end{tabular}

المصدر: الجهاز المركزى للتعبة العامة والاحصاء، التبادل التجارى بين مصر ودول حوض النيل، اعداد مختلقة، 9 1. ب.

ب- التوزيع الجغرافى لقيمة التجارة الخارجية المصرية الكلية الى دول حوض النيل: 
تثير بيانات الجدول رقم (ך)، الى دراسة التوزيع الجغرافى لقيمة التجارة

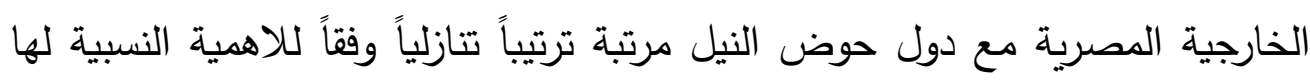

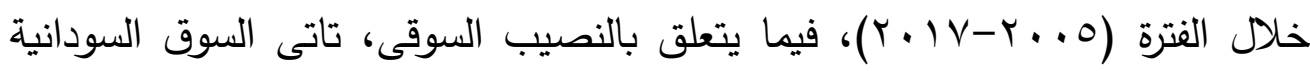
فى المرتبة الاولى، حيث بلغ متوسط قيمة التجارة الخارجية مع تلك السوق خلال فترة

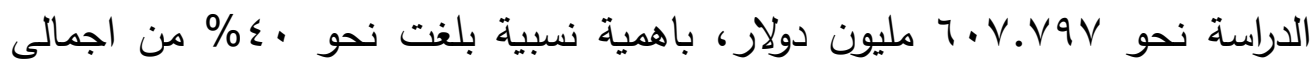
قيمة التجارة الخارجية المصرية مع دول حوض النيل، يليها السوق الكينية، سوق اثيوبيا، سوق اريتريا، سوق أوغندا، سوق الكنغو، سوق تنزانيا، سوق راوندا، وسوق دوق بوروندى، نحو

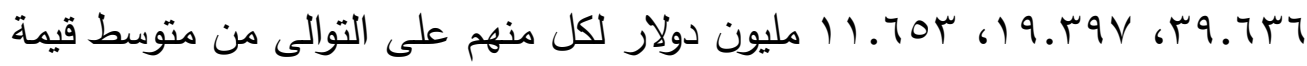

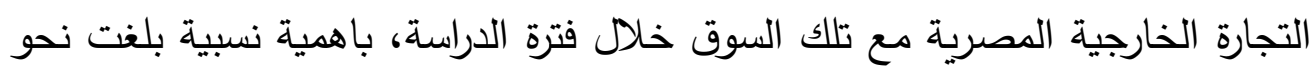

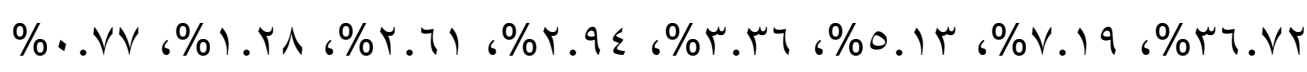
لكل منهم على التوالى من اجمالى قيمة التجارة الخارجية المصرية مع دول حوض النيل، خلال فترة الدراسة.

جدول رقم (7): التوزيع الجغرافى لقيمة التجارة الخارجية المصرية الى دول حوض

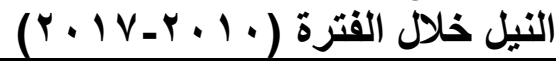

\begin{tabular}{|c|c|c|}
\hline$\%$ & المتوسط بالمليون دولار & 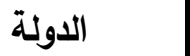 \\
\hline$\{\ldots$ & Y.V.Vav & السودان \\
\hline TY.VY & OOV.AYS & كينيا \\
\hline v.19 & $1.9 .4 \cdot 1$ & أثيوبيا \\
\hline $0.1 \%$ & $\vee \vee .9 \wedge 9$ & اريتريا \\
\hline$r . r 4$ & $01 . .94$ & اوغذا \\
\hline r.q६ & $\{\leqslant .719$ & الكنغو \\
\hline r.T & ra.7rq & تنزانيا \\
\hline $1 . \mathrm{r}$ & $19.49 \mathrm{~V}$ & راوندا \\
\hline.. $\mathrm{VV}$ & $11.70 \mathrm{r}$ & بورندى بو \\
\hline $1 \ldots$ & 1019.117 & الاجمالى \\
\hline
\end{tabular}


المصدر: الجهاز المركزى للتعبة العامة والاحصاء، التبادل التجارى بين مصر ودول حوض النيل، اعداد مختلقة، 9 1.r.

ع - التوزيع الجغرافى لهيكل التجارة الخارجية المصرية مع دول حوض النيل: يتتاول هذا الجزء التوزيع الجغرافى لهيكل التجارة الخارجية المصرية مع دول

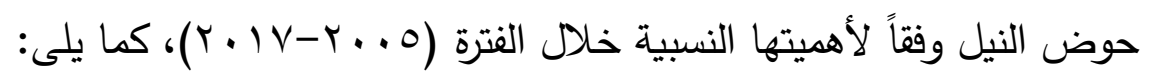
أ- التوزيع الجغرافى لاهم الصادرات المصرية لدول حوض النيل: بدراسة هيكل الصادرات المصرية خلال فترة الدراسة تبين أن ان هناك اربع مجموعات سلعية رئيسية بلغت قيمتها بنحو 90.Y.Y.

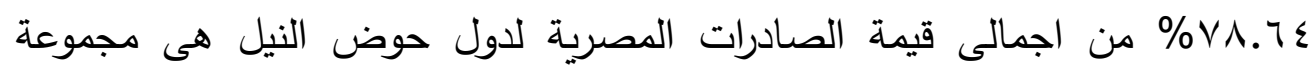

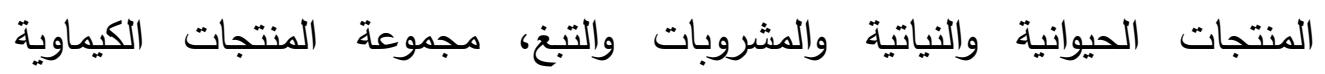

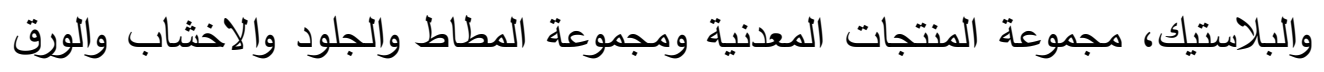

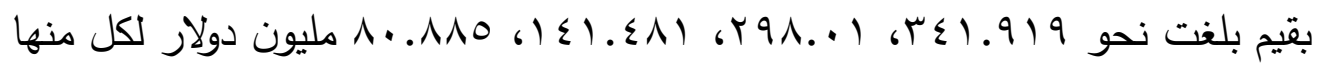

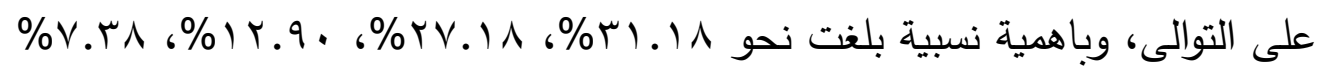
من اجمالى الصادرات المصرية الى دول حوض النيل، كما هو موضتح بالجدول رقم

$$
\text { (). ( ) (9)،(^)، ( ( ) }
$$

- المنتجات الحيوانية والنباتية والمشروبات والتبغ:

بدراسة التوزيع الجغرافى للمنتجات الحيوانية والنباتية والمشروبات والتبغ، كما

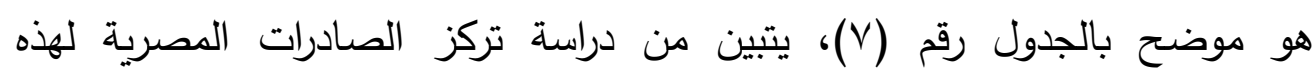

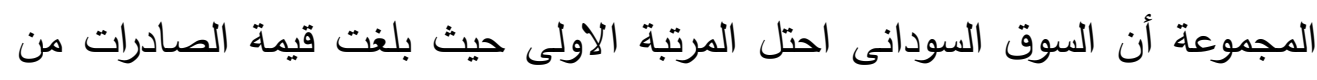

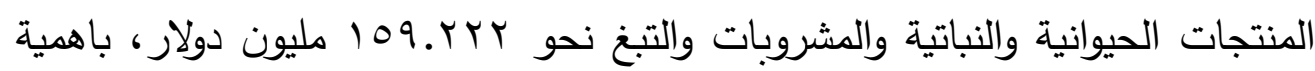

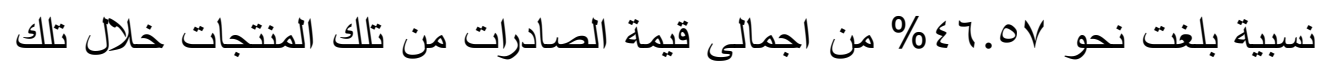

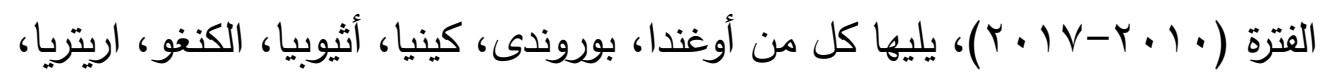

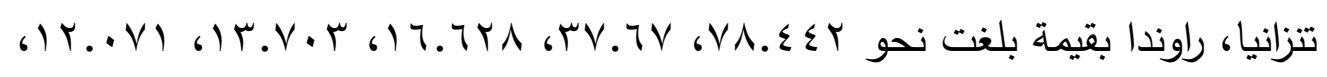

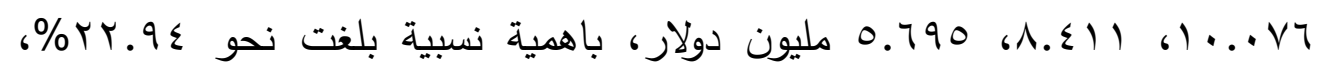

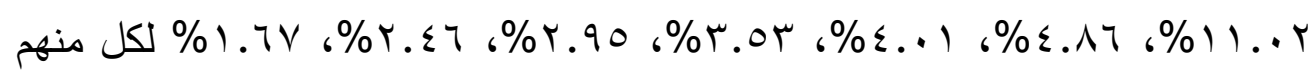
على التوالى من المتوسط خلال فترة الدراسة. 
جدول رقم (V): التوزيع الجغرافى للصادرات المصرية من المنتجات الحيوانية

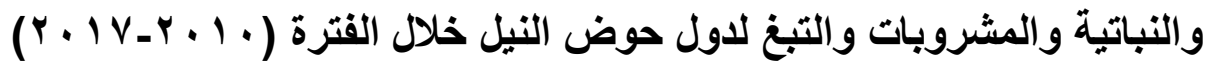

\begin{tabular}{|c|c|c|}
\hline$\%$ & المتوسط بالمليون دولار & 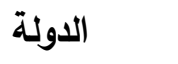 \\
\hline$\leq 7.0 \mathrm{~V}$ & IOQ.YYY & السودان \\
\hline YY.qE & $\vee \wedge . \varepsilon \leqslant Y$ & اوغندا \\
\hline $11 . . r$ & rv. TV & بورندى \\
\hline$\varepsilon . \wedge 7$ & $17.7 \mathrm{r} 1$ & كينيا \\
\hline$\leq \ldots+1$ & $1 r . v \cdot r$ & أثيوبيا \\
\hline r.or & $|r . . v|$ & الكنغو \\
\hline$r .90$ & $1 \cdot \ldots \times 4$ & 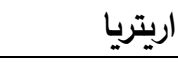 \\
\hline$Y . \leqslant Y$ & $\Lambda . \leqslant 11$ & تنزانيا \\
\hline $1.7 \mathrm{~V}$ & 0.790 & راوندا \\
\hline $1 \ldots$ & $r \leq 1.919$ & 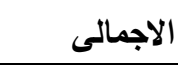 \\
\hline
\end{tabular}

المصدر: الجهاز المركزى للتعبة العامة والاحصاء، التبادل التجارى بين مصر ودول حوض النيل،

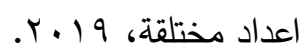

- المنتجات الكيمياوية والبلاستيك: بدراسة التوزيع الجغرافى للمنتجات الكيماوية والبلاستيك، كما هو موضح

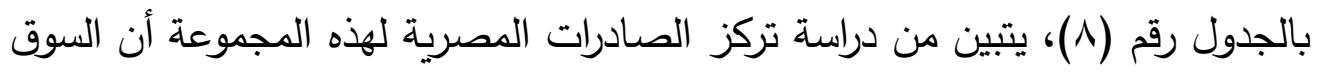
السودانى احتل المرتبة الاولى حيث بلغت قيمة الصادرات من المنتجات الكيمياوية

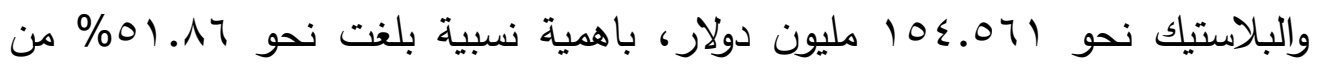

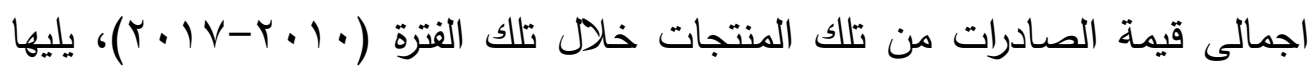
كل من أوغندا، كينيا، أثيوبيا، بوروندى، الكنغو، تتزانيا، راوندا بقيمة بلغت نحو

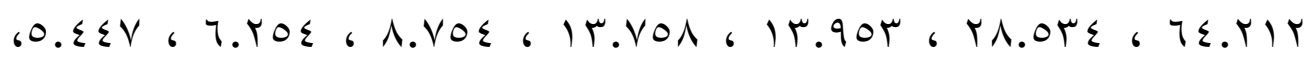

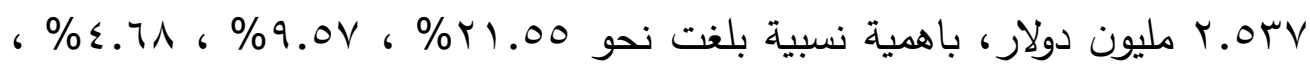

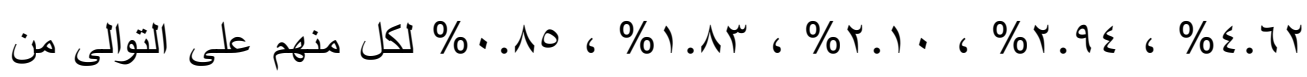
المتوسط خلال فترة الدراس. 
جدول رقم (^): التوزيع الجغرافى للصادرات المصرية من المنتجات الكيماوية

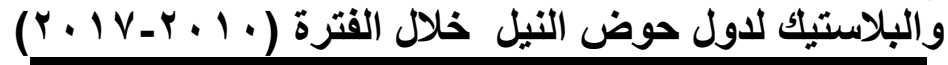

\begin{tabular}{|c|c|c|}
\hline$\%$ & المتوسط بالمليون دولار & الدولة \\
\hline & 104.071 & السودان \\
\hline$r 1.00$ & TE.rIY & | اوغندا \\
\hline $9.0 \mathrm{~V}$ & צN.OY & كينيا \\
\hline 4.71 & 1r.90\% & أثيوبيا \\
\hline צ.T & $1 r . v \circ 1$ & بورندى \\
\hline r.q६ & A.v०\& & الكنغو \\
\hline r.l. & T.YO\& & تنزانيا \\
\hline $1 . \Lambda \pi$ & $0 . \leqslant \leqslant V$ & اريتريا \\
\hline. .10 & r.orv & راوندا \\
\hline $1 \ldots \ldots$ & rqA.. & الاجمالى \\
\hline
\end{tabular}

المصدر: الجهاز المركزى للتعبة العامة والاحصاء، التبادل التجارى بين مصر ودول حوض النيل،

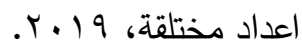

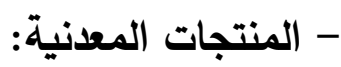

بدراسة التوزيع الجغرافى للمنتجات المعدنية، كما هو موضح بالجدول رقم (9)، يتبين من دراسة تركز الصادرات المصرية لهذه المجموعة أن السوق السودانى احتل

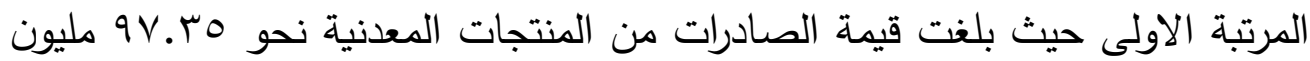

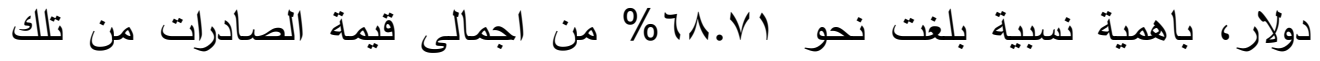

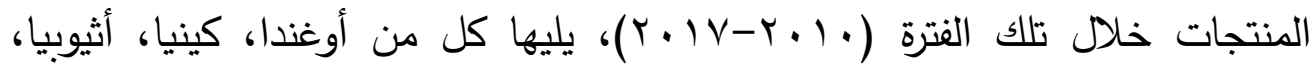

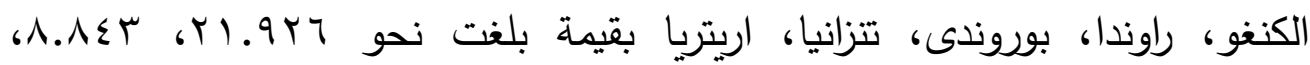
1.

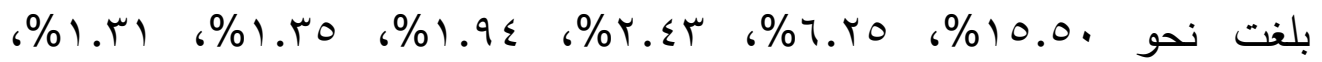

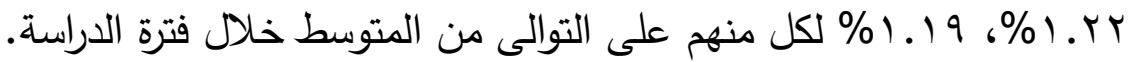


جدول رقم (9): التوزيع الجغرافى للصادرات المصرية من المنتجات المعدنية لدول

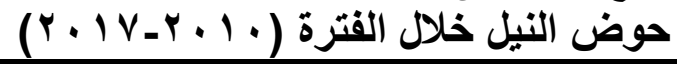

\begin{tabular}{|c|c|c|}
\hline$\%$ & المتوسط بالمليون دولار & الدولة \\
\hline$\neg \wedge . \wedge 1$ & QV.T० & السودان \\
\hline 10.0. & r & اوغندا \\
\hline T.Yo & $\Lambda . \wedge \leq \mu$ & كينيا \\
\hline$r . \varepsilon r$ & $r . \leq \varepsilon 1$ & أثيوبيا \\
\hline $1.9 \varepsilon$ & $r . V \leq V$ & الكنغو \\
\hline D. & $1.9 \cdot v$ & راوندا \\
\hline I.M & 1.10 & بورندى \\
\hline I.rY & $1 . v r q$ & تنزانيا \\
\hline 1.19 & 1.719 & اريتريا \\
\hline $1 \ldots$ & $|\& 1 . \leqslant \wedge|$ & \\
\hline
\end{tabular}

المصدر: الجهاز المركزى للتعبة العامة والاحصاء، التبادل التجارى بين مصر ودول حوض النيل،

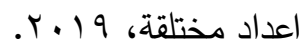

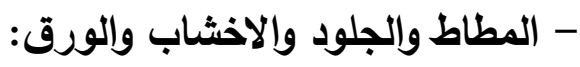
بدراسة التوزيع الجغرافى للمطاط والجلود والاخشاب والورق، كما هو موضح

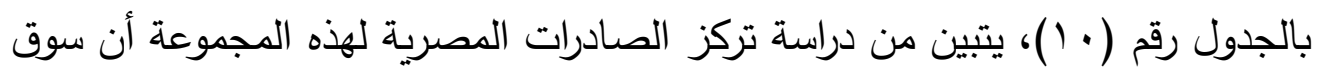

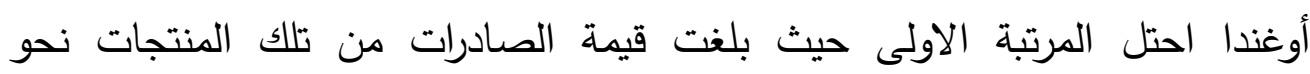

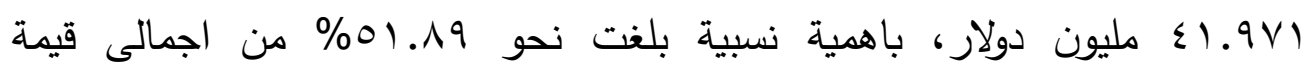

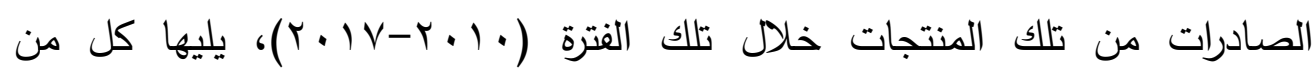
السودان، كينيا، أثيوبيا، تنزانيا، الكنغو، بوروندى، اريتريا، راوندا بقيمة بلغت نحو

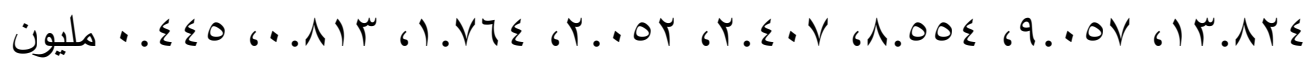

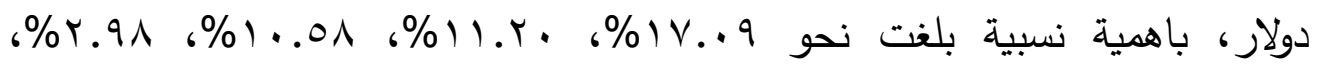

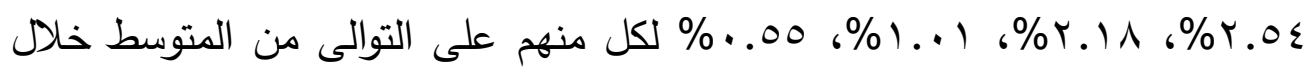


جدول رقم ( • (1): التوزيع الجغرافى للصادرات المصرية من المطاط والجلود

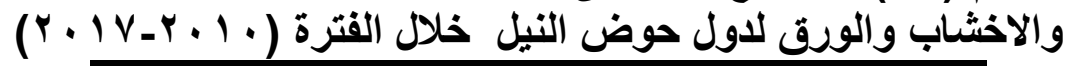

\begin{tabular}{|c|c|c|}
\hline$\%$ & المتوسط بالمليون دولار & الاولة \\
\hline 01.19 & $\$ 1.9 \mathrm{VI}$ & اوغندا \\
\hline $18 . .9$ & IT.AY\& & السودان \\
\hline 11.5. & $9 . .0 V$ & كينيا \\
\hline 1.01 & $1.00 \leqslant$ & أثيوبيا \\
\hline Y.91 & Y.S.V & تنزانيا \\
\hline Y.O & r..Or & الكنغو \\
\hline r.IA & $1 . V 7 \varepsilon$ & بورندى \\
\hline $1 . .1$ & $\cdot . \wedge / \mu$ & اريتريا \\
\hline .00 & $\cdot . \leq \leq 0$ & راوندا \\
\hline $1 \ldots$ & $\wedge . . \wedge \wedge 0$ & \\
\hline
\end{tabular}

المصدر: الجهاز المركزى للتعبة العامة والاحصاء، التبادل التجارى بين مصر ودول حوض النيل،

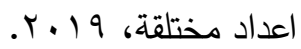

ب- التوزيع الجغرافى لاهم الواردات المصرية من دول حوض النيل: بدراسة هيكل الواردات المصرية خلال فترة الدراسة تبين أن هناك مجموعتان

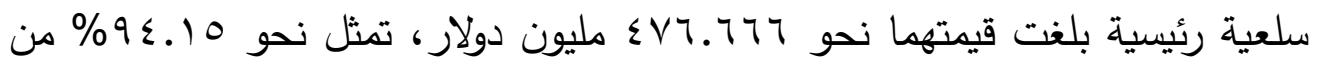
اجمالى قيمة الواردات المصرية من دول حوض النيل هى مجموعة المنتجات الحيوانية

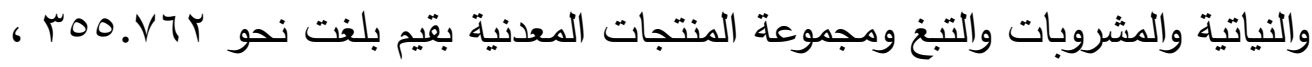

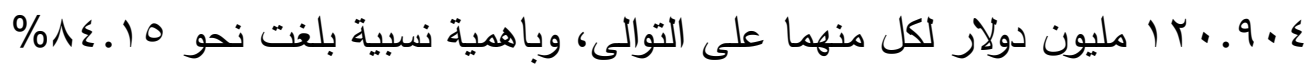
، · ( من اجمالى الواردات المصرية من دول حوض النيل، كما هو موضح

$$
\text { بالجدول رقم (1') - (1) ، (1) (1). }
$$

- المنتجات الحيوانية والنباتية والمشروبات والتبغ:

بدراسة التوزيع الجغرافى للمنتجات الحيوانية والنباتية والمشروبات والتبغ، كما هو موضتح بالجدول رقم (1)، يتبين من دراسة تركز الواردات المصرية لهذه

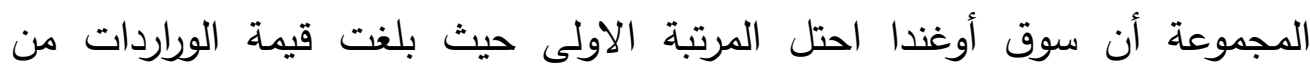




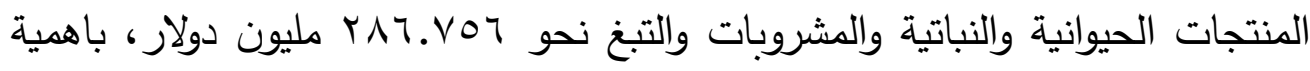

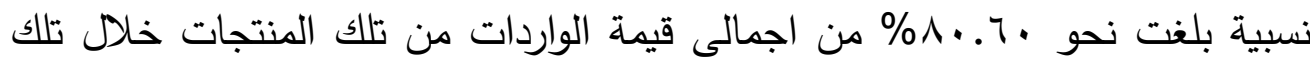

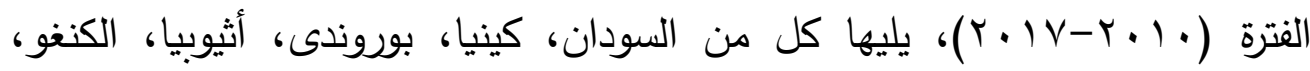

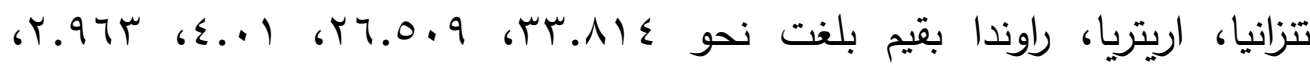

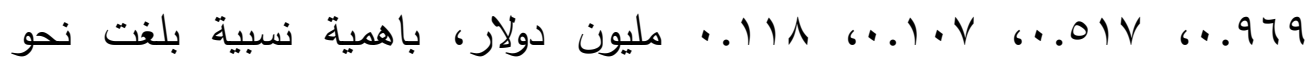

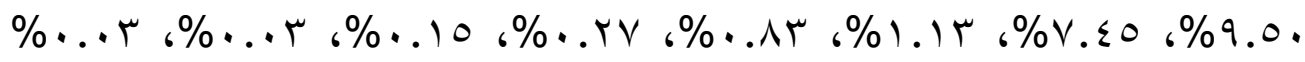

لكل منهم على التوالى من المتوسط خلال فترة الدراسة . جدول رقم (1 (1): التوزيع الجغرافى للواردات المصرية من المنتجات الحيوانية

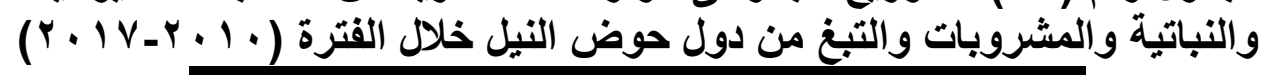

\begin{tabular}{|c|c|c|}
\hline$\%$ & المتوسط بالمليون دولار & الاولة \\
\hline A... & YAT.VOY & |وغندا \\
\hline 9.0. & $r r . \Lambda 1 \leqslant$ & السودان \\
\hline$v . \leqslant 0$ & r..0.9 & كينيا \\
\hline $1.1 \%$ & $\varepsilon \ldots 1$ & بورندى \\
\hline..$\wedge \mu$ & r.94 & أثيوبيا \\
\hline . rV &. .979 & الكنغو \\
\hline .10 &. $.01 \mathrm{~V}$ & تنزانيا \\
\hline$\ldots r$ &. $.1 \cdot v$ & اريتريا \\
\hline$\ldots r$ &. .111 & راوندا \\
\hline $1 \ldots$ & roo.vqr & الاجمالى \\
\hline
\end{tabular}

المصدر: الجهاز المركزى للتعبة العامة والاحصاء، التبادل التجارى بين مصر ودول حوض النيل،

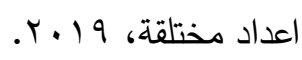

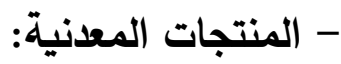

بدراسة التوزيع الجغرافى للمنتجات المعدنية، كما هو موضح بالجدول رقم

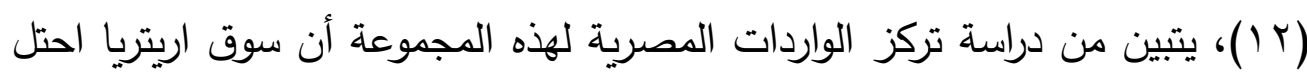

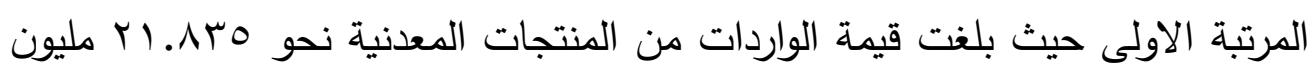

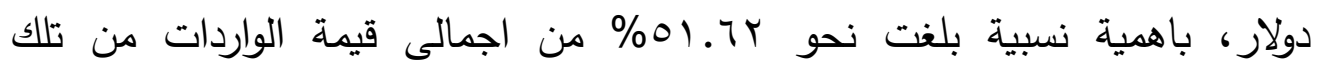


ياسر عبد الر اضي وآخرن، دراسة تحليلية للهيكل السلعى للتجارة الخارجية المصرية...

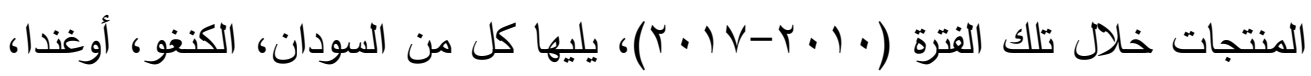

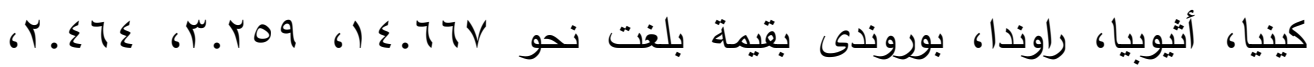

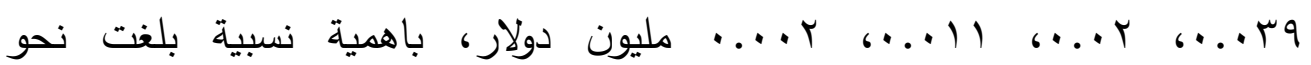
\%

منهم على التوالى من المتوسط خلال فترة الدراسة.

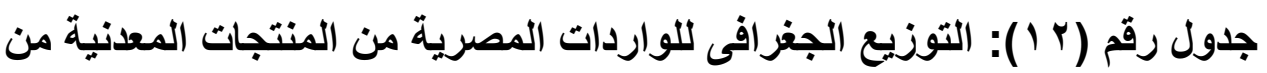

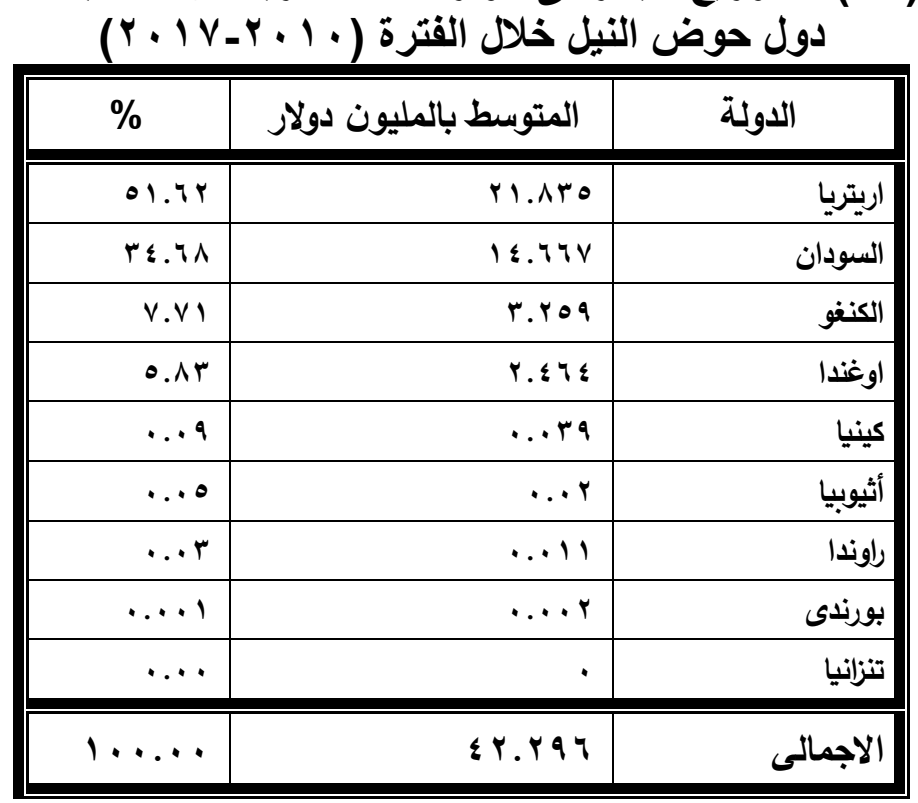

المصدر: الجهاز المركزى للتعبة العامة والاحصاء، التبادل التجارى بين مصر ودول حوض النيل،

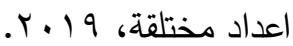

ج- التوزيع الجغرافى لاهم الهيكل السلعى للتجارة الخارجية المصرية لاول حوض

النيل:

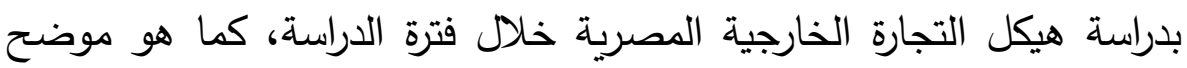
بالجدول رقم (ب ())، (ع ()، (0) (1)، تبين أن ان هنآك ثلاث مجموعات سلعية رئيسية

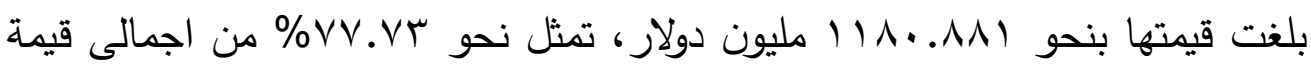
التجارة الخارجية المصرية مع دول حوض النيل هلى لنى مجموعة المنتجات الحيوانية

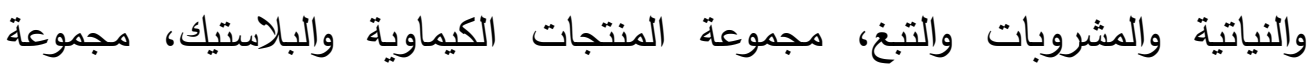

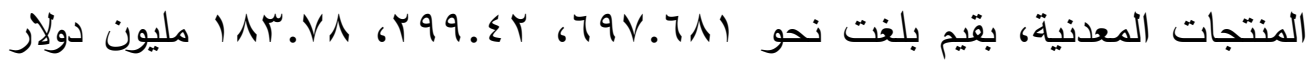

$$
(104)
$$




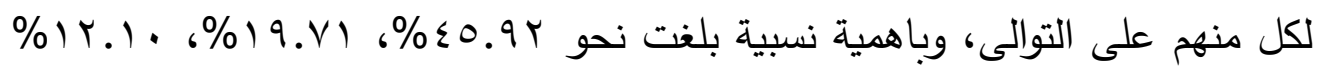

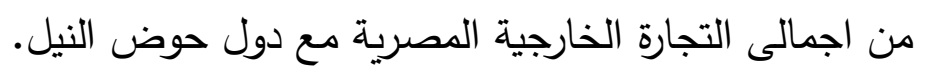
- المنتجات الحيوانية والنباتية والمشروبات والتبغيغ:

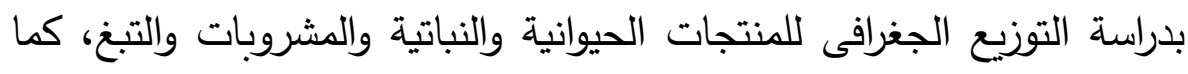

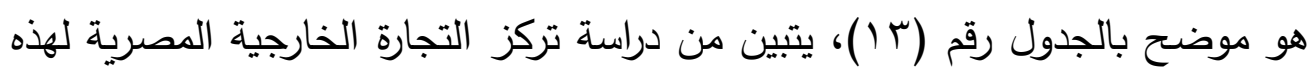

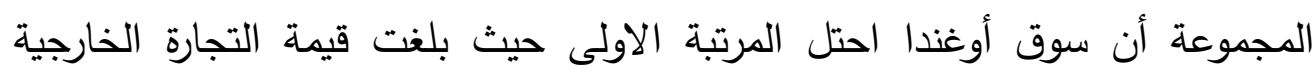

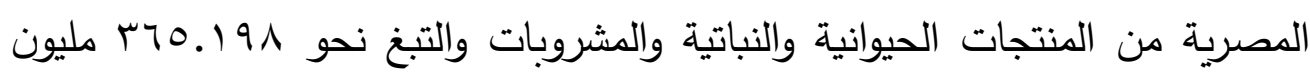

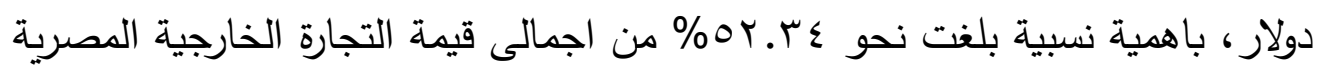

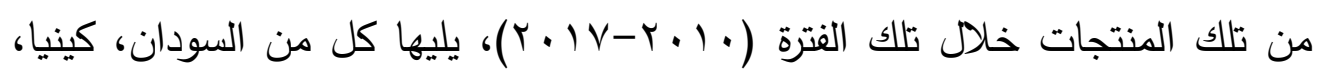

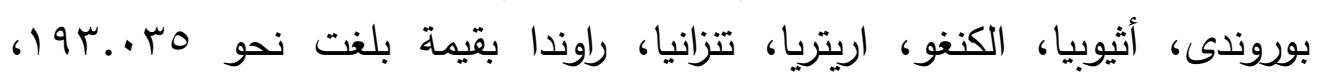

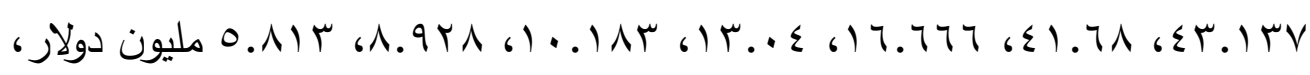

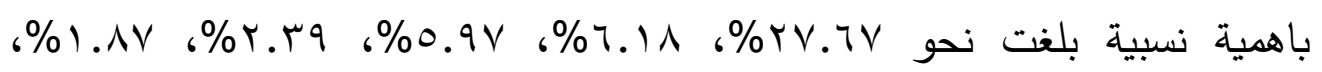

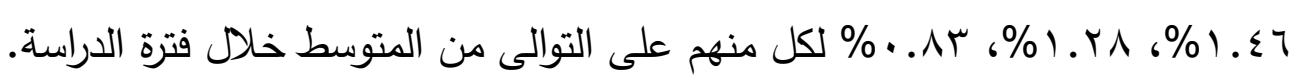

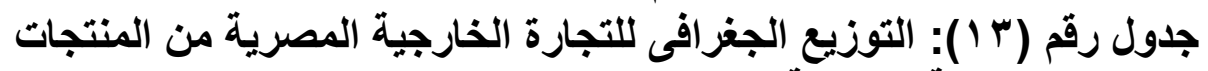

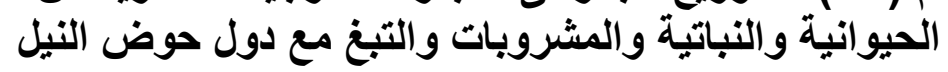

\begin{tabular}{|c|c|c|}
\hline$\%$ & المتوسط بالمليون دولار & الاولة \\
\hline Or.rs & 490.191 & | اوغندا \\
\hline TV.TV & $194 . .40$ & السودان \\
\hline 8.11 & $\varepsilon r .1 T V$ & كينيا \\
\hline $0.9 \mathrm{~V}$ & $\$ 1.71$ & بورندى \\
\hline r.r. & 17.747 & أثيوبيا \\
\hline I.Av & $1 \% . .5$ & الكنغو \\
\hline 1.47 & $1 . .1 \wedge r$ & اريتريا \\
\hline $1 . \Gamma \wedge$ & $\Lambda .9 r \wedge$ & تنزانيا \\
\hline.$\wedge r$ & 0.114 & راوندا \\
\hline $1 \ldots \ldots$ & 998.711 & الاجمالى \\
\hline
\end{tabular}

المصدر: الجهاز المركزى للتعبة العامة والاحصاء، التبادل التجارى بين مصر ودول حوض النيل،

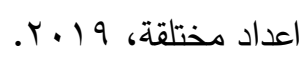




\section{- المنتجات الكيمياوية والبلاستيك:}

بدراسة التوزيع الجغرافى للمنتجات الكيماوية والبلاستيك، كما هو موضح بالجدول رقم (ع ())، يتبين من دراسة تركز التجارة الخارجية المصرية لهذه المجموعة

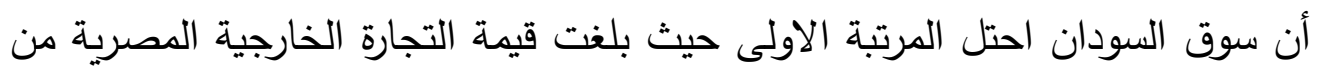

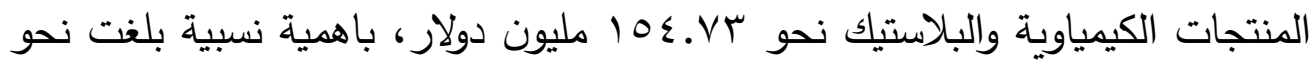

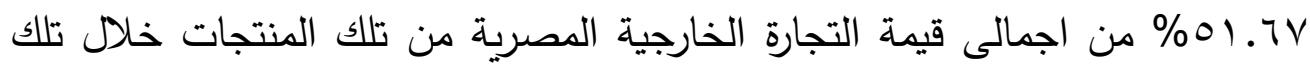

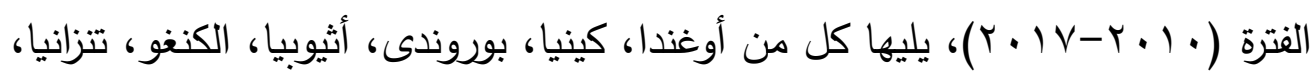

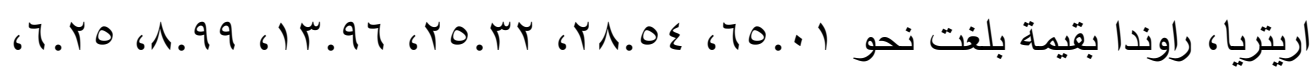

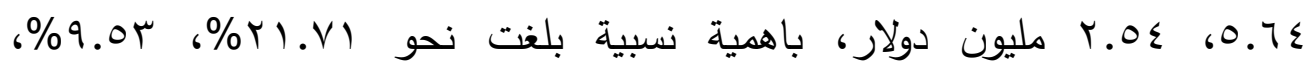

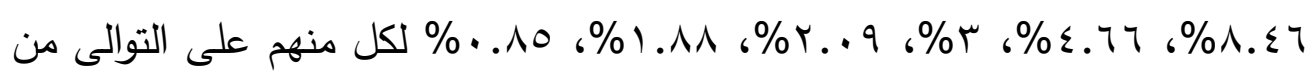
المتوسط خلال فترة الدراسة. جدول رقم (؛ 1): التوزيع الجغرافى للتجارة الخارجية المصرية من المنتجات المنات

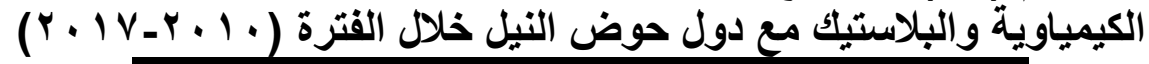

\begin{tabular}{|c|c|c|}
\hline$\%$ & المتوسط بالمليون دولار & الالدولة \\
\hline $01.7 \mathrm{~V}$ & los.VY & السودان \\
\hline YI.VI & $70 . .1$ & اوغندا \\
\hline 9.04 & rA.0 & كينيا \\
\hline$\wedge . \leqslant 7$ & ro.rr & 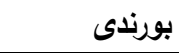 \\
\hline$\varepsilon .77$ & 17.97 & أثيوبيا \\
\hline r... & 1.99 & الكنغو \\
\hline r.. q & T.YO & ت ت ت تززانيا \\
\hline $1 . \wedge \wedge$ & $0.7 \leq$ & اريتريا \\
\hline.$\wedge 0$ & r.o\& & 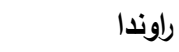 \\
\hline $1 \cdots \cdot$ & rq9.\&r & الاجمالى \\
\hline
\end{tabular}

المصدر: الجهاز المركزى للتعبة العامة والاحصاء، التبادل التجارى بين مصر ودول حوض النيل،

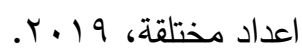




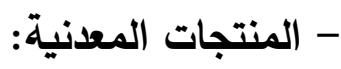

بدراسة التوزيع الجغرافى للمنتجات المعدنية، كما هو موضح بالجدول رقم

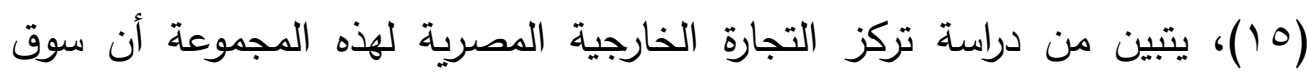
السودان احتل المرتبة الاولى حيث بلغت قيمة التجارة الخارجية المصرية من المنتجات

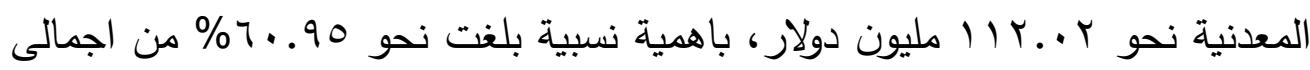

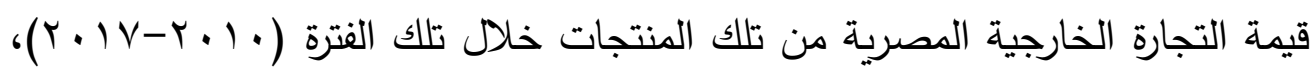
يليها كل من أوغندا، إريتريا، كينيا، الكنغو، أثيوبيا، راوندا، بوروندى، تنزانيا بقيمة بلغت نحو 9r.r دولار، باهية نسبية بلغت نحو ب.r.

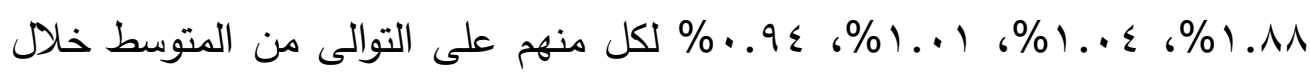
فترة الدراسة

جدول رقم (0 1 ): التوزيع الجغرافى للتجارة الخارجية المصرية من المنتجات

\begin{tabular}{|c|c|c|}
\hline$\%$ & المتوسط بالمليون دولار & الدولة \\
\hline 7.90 & Hr..r & السودان \\
\hline Ir.rV & r\&.rq & | اوغندا \\
\hline Ir.A. & rr.or & اريتريا \\
\hline 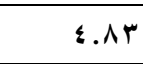 & $\wedge . \wedge \wedge$ & كينيا \\
\hline r.rV & 9.1 & الكنغو \\
\hline 1.11 & $r . \leqslant 4$ & أثيوبيا \\
\hline $1 . .5$ & $1.9 r$ & راوندا \\
\hline $1 . .1$ & 1.10 & بورندى \\
\hline .99 & $1 . v r$ & تنزانيا \\
\hline $1 \ldots \ldots$ & IAr.vA & الاجمالى \\
\hline
\end{tabular}

المصدر: الجهاز المركزى للتعبة العامة والاحصاء، التبادل التجارى بين مصر ودول حوض النيل، اعداد مختلقة، 99 .r. 
خامساً: كفاءة التجارة الخارجية المصرية مع دول حوض النيل

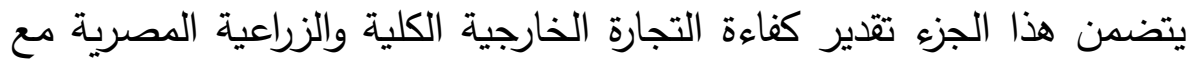

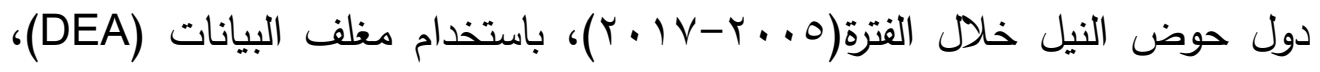
حتى يمكن الاسترشاد بها عند توجيه متخذى القرار الى كيفية تحقيق كفاءة التجارة الخارجية الكلية والزراعية مع هذه الدول. الدئ. أولاً: الفروض البحثية التحليلية: 1 أبات العائد للسعة(CRS):

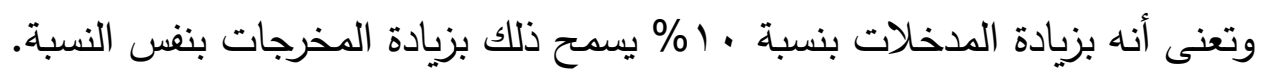

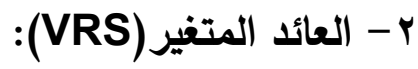
أ- العائد المتزايد(IRS):

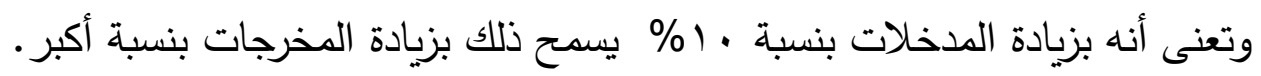

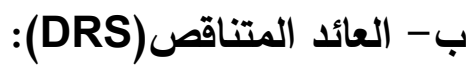

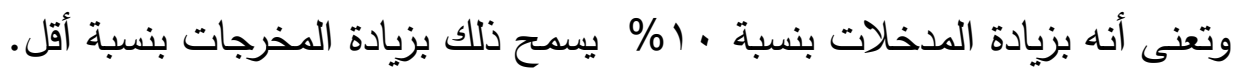
ثانياً: نموذج تحليل الكفاءة لمغلف البيانات للتجارة الخارجية الكلية المصرية: $E X i j=F(P O j, G D P j$, Dij)

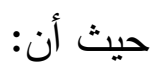

EXij : قيمة التجارة الكلية المصرية (i) إلى دول حوض النيل (j)، أو وحدات اتخاذ

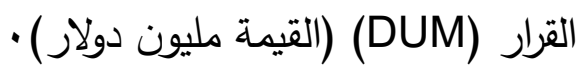

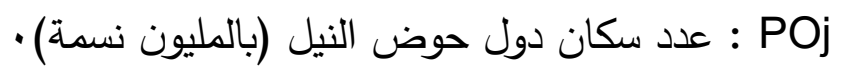

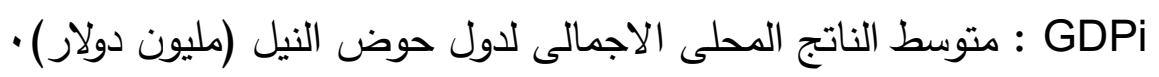

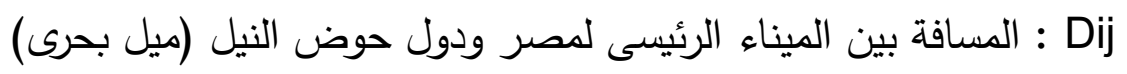

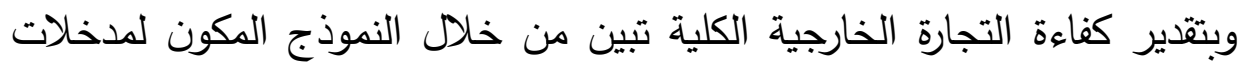

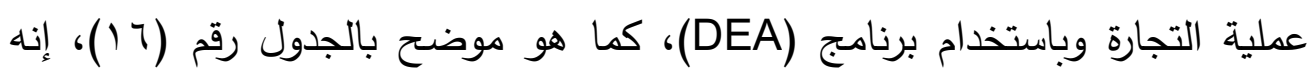

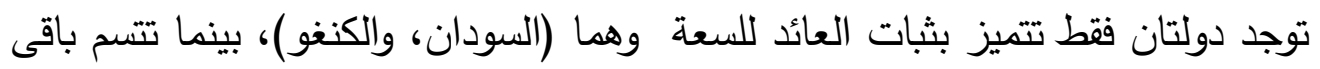

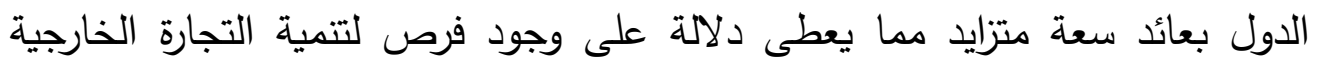
الكلية المصرية إلى تلك الدول. 
1- تقدير كفاءة التجارة الخارجية الكلية المصرية مع دول حوض النيل فى ظل فرضية ثبات العائد للسعة:

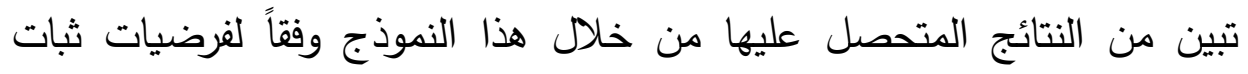

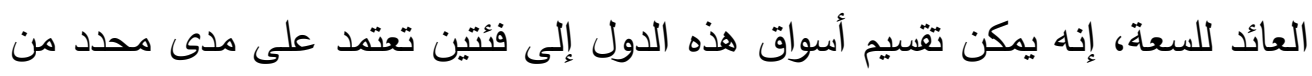

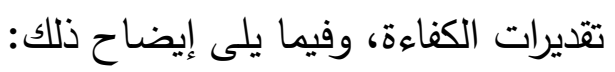

أ- الأسواق ذات الكفاءة الكاملة:

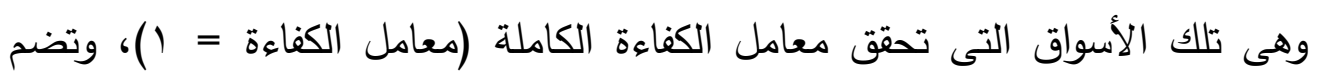

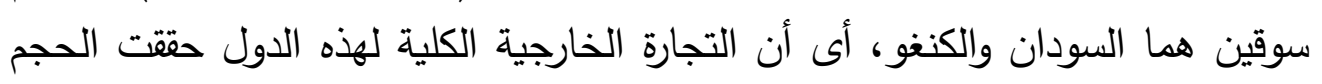
الأمثل.

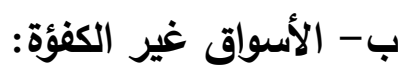

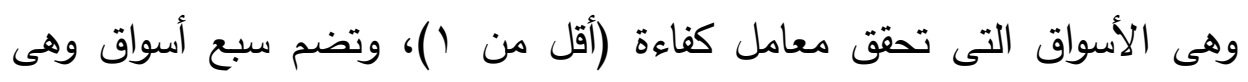

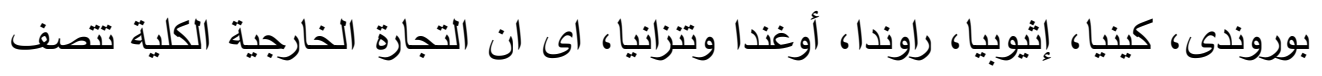

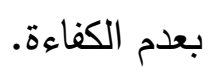
ץ- تقدير كفاءة التجارة الخارجية الكلية المصرية مع دول حوض النيل فى ظل فرضية تغير العائد للسعة:

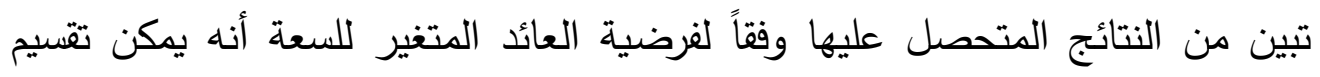

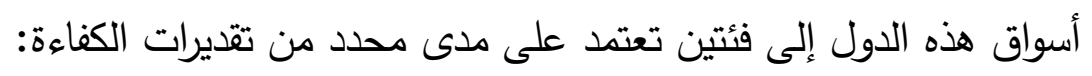
أ- الأسواق ذات الكفاءة الكاملة:

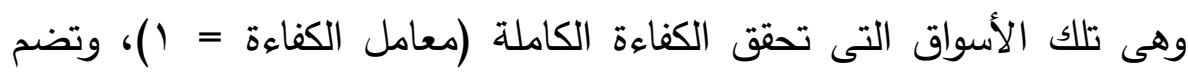

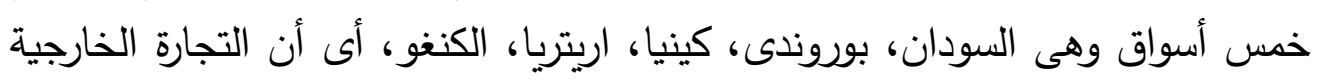
الكلية تحقق الحجم الأمثل.

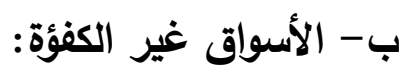

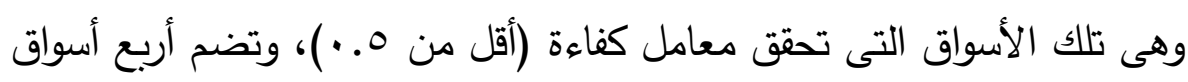

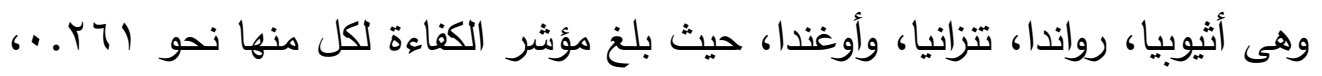

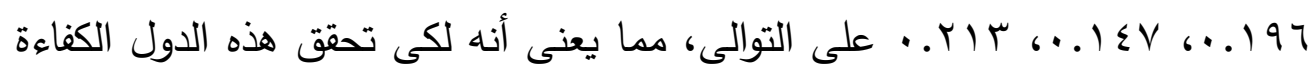

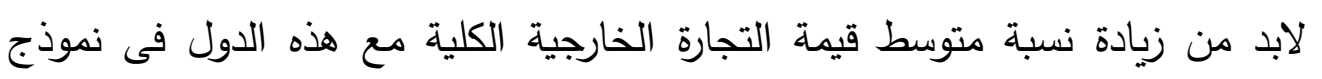

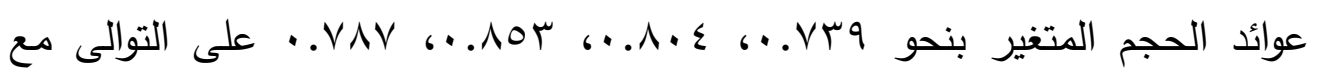
افتراض ثبات مستويات الدخخلات. 


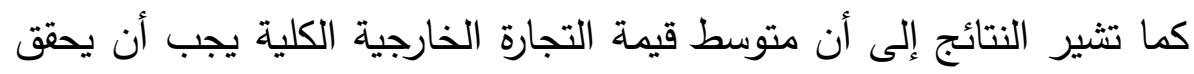

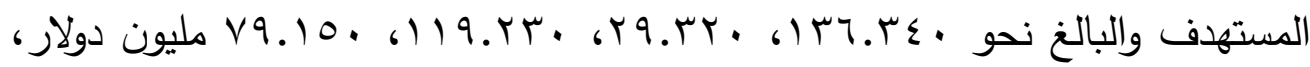

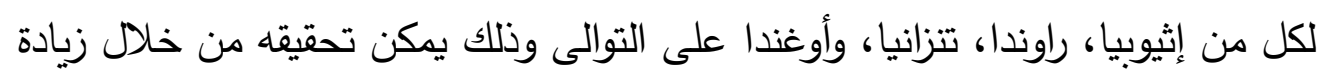
حجم الصادرات لهذه الدول. جدول رقم (7 1 ): مدخلات ونتائج تحليل نموذج مغلف البيانات (DEA) لتقدير كفاءة

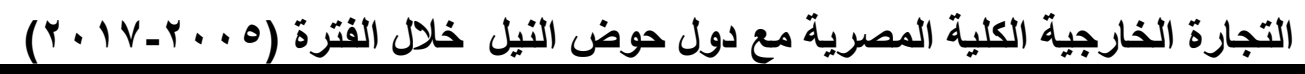

\begin{tabular}{|c|c|c|c|c|c|c|c|c|c|}
\hline \multirow[b]{2}{*}{ المستهدف } & \multirow{2}{*}{ عائد } & \multirow{2}{*}{$\begin{array}{l}\text { كفاءة } \\
\text { S,E }\end{array}$} & \multicolumn{2}{|c|}{ كفاءة التجارة } & \multicolumn{4}{|c|}{ مدخلات النموذج } & \multirow{2}{*}{ وحدة اتخاذ } \\
\hline & & & متغيز & $\begin{array}{l}\text { ثابت } \\
\text { Crs }\end{array}$ & المسافة & الاجملى الملى & (مليون & الخارجية التصرية & \\
\hline $7 . \vee . \vee 9 V$ & ثابت & 1 & 1 & 1 & $90 \leq . V \leq$ & TAYI & ro.ov & T.V.VqV & السودان \\
\hline $11.70 \mathrm{r}$ & متزايد &. .117 & 1 &.$M 17$ & $Y \cdot V V .7 q$ & YIV. & $\Lambda . r$ & $11.70 \mathrm{r}$ & بورندى \\
\hline OOV.AYE & متناقص & $\cdot .190$ & 1 & $\cdot .190$ & $199 Y . \varepsilon Y$ & $\leqslant 990$ & $\varepsilon r . Y V$ & OOV.AYE & كينيا \\
\hline$\vee \vee .9 \wedge 9$ & متزايد & . & 1 &.+47 & $11 \cdot 0 . \cdot v$ & 19. & T.Y & $\vee \vee .9 \wedge 9$ & اريتريا \\
\hline$\varepsilon \varepsilon .719$ & ثابت & 1 & 1 & 1 & rM. I.rr & Y410 & IV.YV & $\leq \varepsilon .719$ & الكنغو \\
\hline IM.ru & متناقص & .941 &.$Y 71$ & $\cdot r \leqslant r$ & $1 \leq Y \leq .17$ & EIrT & $9 . .70$ & $1 \cdot 9.4 \cdot 1$ & أثيوبيا \\
\hline rq.rY & متناقص &.$v \vee 1$ & .197 & .101 & $1994 . \wedge \varepsilon$ & TrV. & 1.rrr & 19.rqV & راوندا \\
\hline $119 . \mathrm{rr}$ & متناقص & $\cdot . \wedge \vee V$ & $-1 \leq V$ & $.11 \times 9$ & $Y r \leqslant 0 . Y q$ & $r q \cdot r$ & $\varepsilon \cdot \ldots \cdot r$ & ra.7ra & تنزانيا \\
\hline$v 9.10$ & متناقص & $\cdot . \vee \wedge \varepsilon$ & ATIY & .178 & $1 \wedge 7 \cdot .7 V$ & 1971 & rT.Ar & $01 . .94$ & |وغندا \\
\hline- & - & $\cdot .9 r \wedge$ & . Orr & -.291 & - & - & - & - & المتوسط \\
\hline
\end{tabular}

المصدر: نتائج تحليل بيانات التجارة الخارجية الكلية المصرية مع دول حوض النيل على الحاسب الالى باستخدام نموذج مغلف البيانات (DEA).

وبذلك يتضح أن الاسواق التى حققت التجارة الكلية معها كفاءة تامة يبلغ

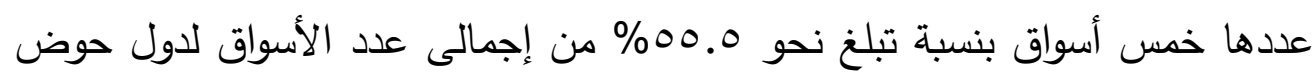
النيل، فى حين بلغ عدد الأسواق التى لم تحقق التجارة الكلية معها كفاءة تامة أربع أسواق بنسبة تبلغ نحو ه.ء ؛ م من إجمالى عدد الأسواق لدول حوض النيل وتراوحت 


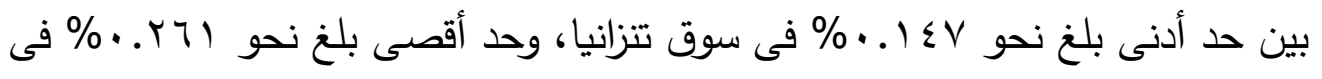
السوق الأثيوبية.

ثانياً: نموذج تحليل الكفاءة مغلف البيانات للتجارة الخارجية الزراعية المصرية: EXij = F(POj, GDPj, Dij)

حيث أن:

EXij وحدات اتخاذ القرار (DUM) (القيمة مليون دولار ). POj : عدد سكان دول حوض النيل (بالمليون نسمة).

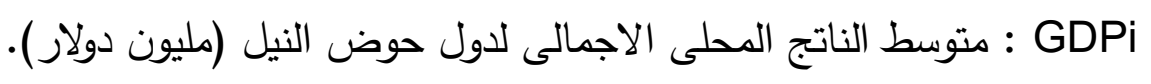

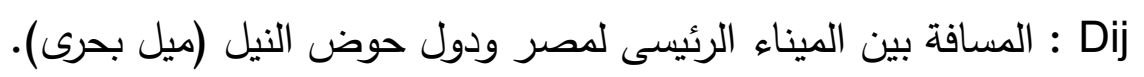

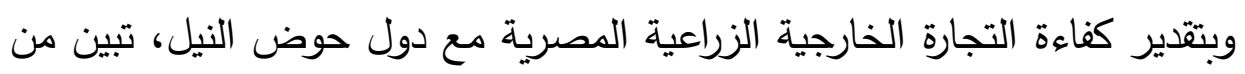

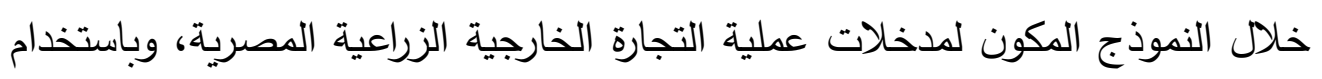

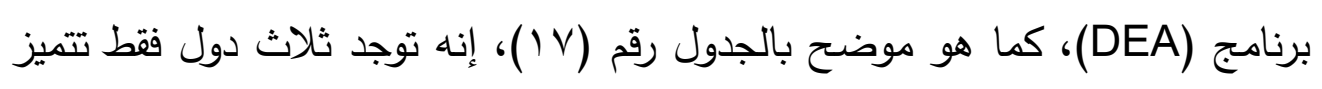

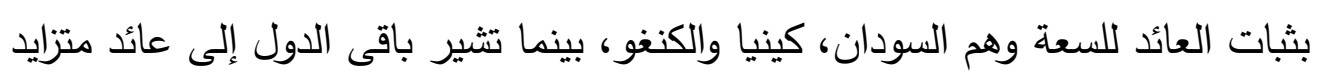

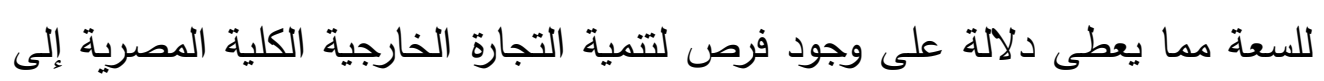
تلك الدول. 1- تقدير كفاءة التجارة الخارجية الزراعية المصرية مع دول حوض النيل فى ظل

\section{فرضية ثبات العائد للسعة:}

تبين من النتائج المتحصل علئها مل لمعه: خلال هذا النموذج وفقاً لفرضيات ثبات

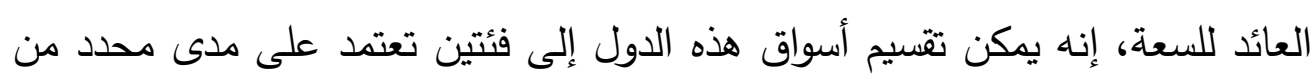
الكفاءة:

أ- الأسواق ذات الكفاءة الكاملة:

وهى تلك الأسواق التى تحقق معامل الكفاءة الكاملة (معامل الكفاءة = ())،

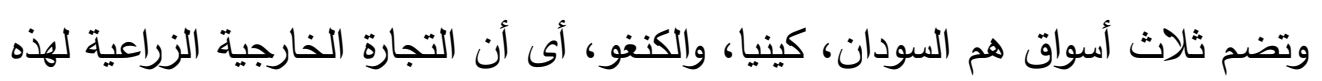

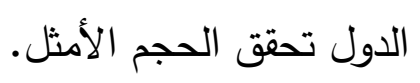




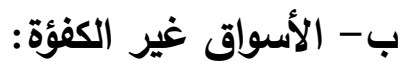

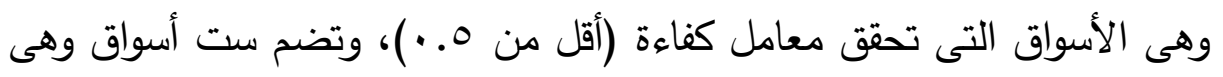

بوروندى، اريتريا، إثيوبيا، راوندا، تنزانيا، أوغندا، ایى ان التجارة الخارجية الزراعية تتصف بعدم الكفاءة. ץ- تقدير كفاءة التجارة الخارجية الزراعية المصرية مع دول حوض النيل فى ظل

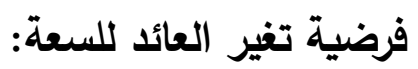
تبين من النتائج المتحصل عليها وفقاً لفرضية العائد المتغير للسعة أنه يمكن تقسيم أسواق هذه الدول إلى فئتين تعتمد على مدى محدد من تقديرات الكفاءة: أ- الأسواق ذات الكفاءة الكاملة: وهى تلك الأسواق التى تحقق الكفاءة الكاملة (معامل الكفاءة = ())، وتضم أربع أسواق وهى السودان، بوروندى، كينيا والكنغو، أى أن التجارة الخارجية الكلية الكانية

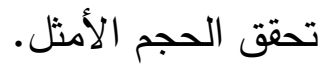

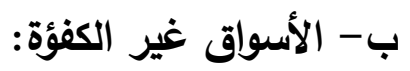
وهى تلك الأسواق التى تحقق معامل كفاءة (أقل من ه . )، وتضم خمس

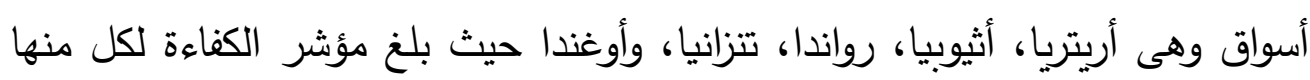

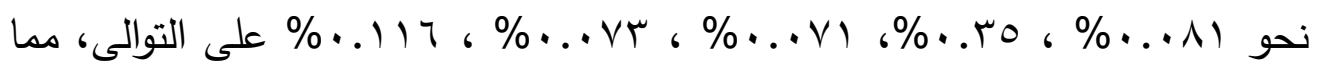

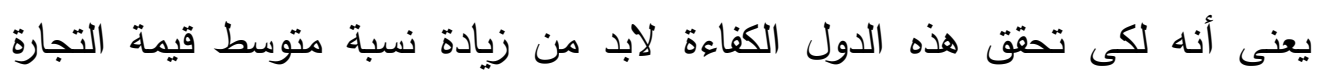

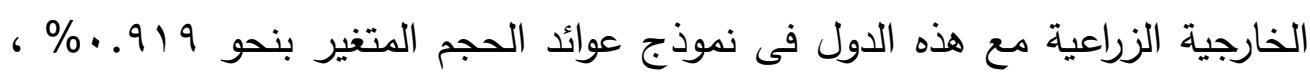

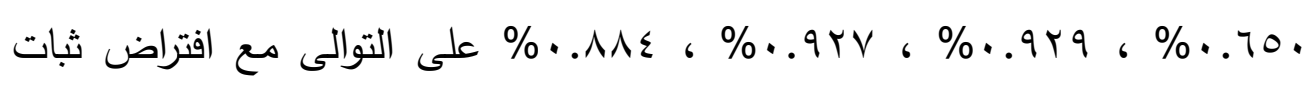

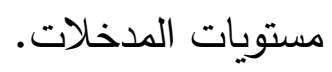

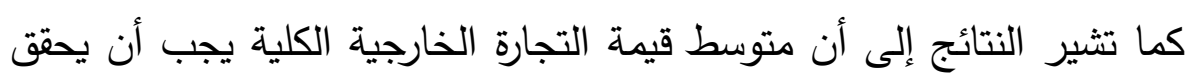

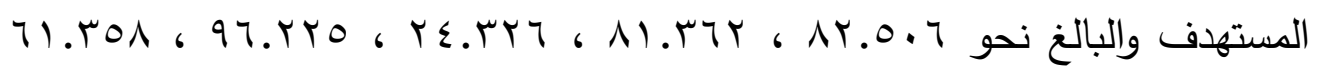


مليون دولار ، لكل من اريتريا، إثيوبيا، راوندا، تنزانيا، وأوغندا على التوالى وذلك يمكن تحقيقه من خلال زيادة حجم الصادرات لهذه الدول. وبذلك يتضح أن الاسواق التى حققت التجارة الخارجية الزراعية معها كفاءة

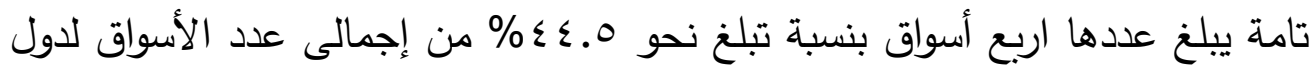

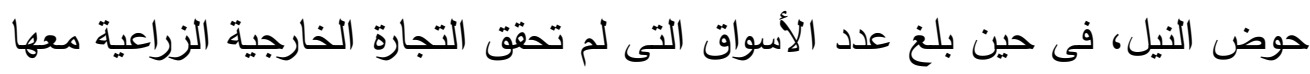

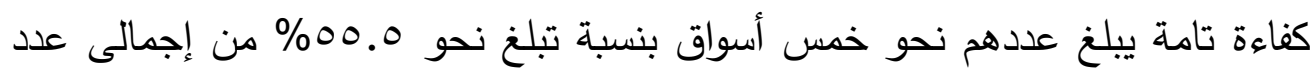

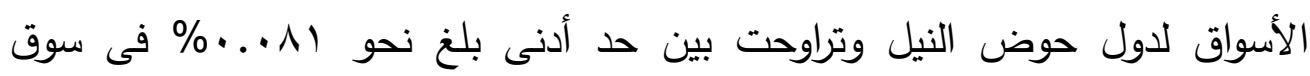

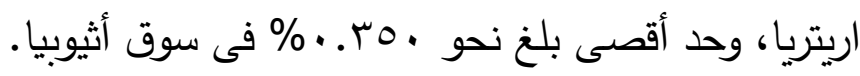
جدول رقم (IV) : مدخلات ونتائج تحليل نموذج مغلف البيانات (DEA) لتقدير كفاءة

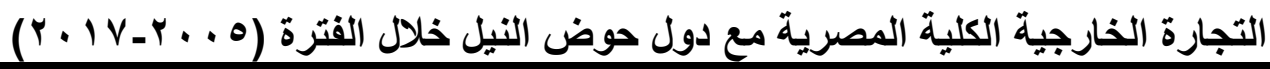

\begin{tabular}{|c|c|c|c|c|c|c|c|c|c|}
\hline \multirow{2}{*}{ المستهدف } & \multirow{2}{*}{ عائد } & \multirow{2}{*}{$\begin{array}{l}\text { كفاءة } \\
\text { S,E }\end{array}$} & \multicolumn{2}{|c|}{$\begin{array}{c}\text { الخارجية المصرية التجارة } \\
\text { (C,E) }\end{array}$} & \multicolumn{4}{|c|}{ مدخلات النموذج } & \multirow{2}{*}{$\begin{array}{c}\text { وحدة } \\
\text { التراذ } \\
\text { (DMU) }\end{array}$} \\
\hline & & & $\begin{array}{l}\text { متغير } \\
\text { Vrs }\end{array}$ & $\begin{array}{l}\text { ثابت } \\
\text { Crs }\end{array}$ & البالميل & الاجمالى & 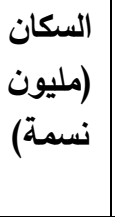 & الخارجية التجارة & \\
\hline $99.01 \mathrm{~V}$ & |ثابت & 1 & 1 & 1 & $90 \leq . V \leq$ & YAYI & ro.0v & $97.01 \mathrm{~V}$ & السودان \\
\hline$r . \wedge \leq$. & |متزايد & $. .1 \leqslant$ & 1 & $. .1 \leqslant$ & Y.VV.YT & rIV. & N.r & 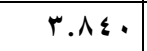 & بورندى \\
\hline 114.099 & |ثابت & 1 & 1 & 1 & $1994 . \leqslant Y$ & $\leqslant 790$ & $\varepsilon r . r V$ & 114.099 & \\
\hline AY.0.T & |متناقص & $.9 \wedge \mathrm{V}$ & $\cdots \wedge 1$ &..$\Lambda$ & $11.0 .0 v$ & $19 \ldots$ & $r . r \leq$ & r. 1.091 & اريتريا \\
\hline $9.0 Y$. & ثابت & 1 & 1 & 1 & $r r \cdot 1 . r r$ & rभा० & TV.YV & 7.0Y. & | الكنغو \\
\hline NI.rgr & متزايد & $\because v \otimes v$ &.$r \Delta$ &. . 70 & $1 \leq r \leq .17$ & \&Irr & $9 . .70$ & 17.ror & أثيوبيا \\
\hline YE.rYT & |متناقص & $.9 \leq r$ & $\ldots \times 1$ & $\ldots 7 V$ & $1994 . \Lambda \leq$ & TYV. & $1 . r r$ & $r .9 .7$ & راوندا \\
\hline 9Y.YYO & |متناقص & $\therefore 9 \leqslant 0$ & $\ldots v r$ & $\ldots 99$ & $r r \leqslant 0 . r Y$ & Mq.r & $\varepsilon \ldots r$ & $\leq .7 \leqslant 7$ & تنزانيا \\
\hline $71 . r 01$ & متناقص & .9 .0 & .0118 & .1 .0 & $114 . .7 \mathrm{~V}$ & 1971 & rr.Ar & $\Lambda .1 \mathrm{~V}$. & |وغندا \\
\hline- & - & $\because v 0$. &..$\leqslant 17$ & . & & - & - & - & |المتوسط \\
\hline
\end{tabular}

المصدر: نتائج تحليل بيانات التجارة الخارجية الكلية المصرية مع دول حوض النيل على الحاسب الالى باستخدام نموذج مغلف البيانات (DEA). 


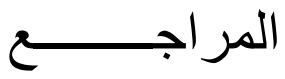

1- البنك الدولى، " مؤشرات التنمية العالمية " ، اعداد متفرقة.

ץ- الجهاز المركزى للتعبئة العامة والاحصاء، " نشرة التجارة الخارجية " ، اعداد

متفرقة.

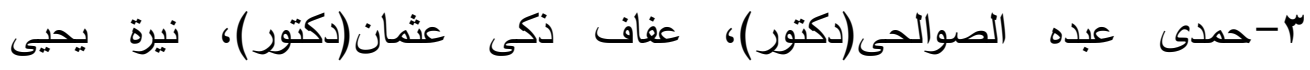
سليمان(دكتور)، فاطمة أحمد شفيق(دكتور)، " امكانية تنمية العلاقات الاقتصادية المصرية مع دول حوض النيل " ، الجمعية المصرية للاقتصاد الزراعى، المؤتمر

$$
\text { الثامن عشر للاقتصادين الزراعيين، اكتوبر، . • r. }
$$

צ-سعيد ححم المهيلمى(دكتور)، طارق مصطفى غلوش (دكتور)، محمد فوزى طه عبد العال، "العلاقات التجارية بين جمهورية مصر العربية ودول حوض النيل (اقتراحات لتدعيمها وتنشيطها)"، جامعة المنصورة، كلية التجارة، المجلة المصرية

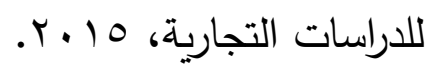

ه-ممدوح البدرى محم (دكتور)، "امكانيات الاستثمار الزراعى فى دول حوض النيل"، الجمعية المصرية للاقتصاد الزراعى، المؤتمر الثامن عشر للاقتصادين الزراعيين،

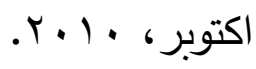

צ-محسن البطران (دكتور)، فاطمة حامد (دكتور)، "دراسة اقتصادية للعلاقات التجارية البينية بين مصر ودول حوض النيل بين الواقع والمامول"، الجمعية المصرية للاقتصاد الزراعى، المؤتمر الثامن عشر للاقتصادين الزراعيين، اكتوبر،

$$
. r \cdot 1 \text {. }
$$

V- حمح فوزى طه عبد العال، "توسيع وتدعيم مجالات التعاون الاقتصادى بين جمهورية مصر العربية ودول حوض النيل فى ضوء المزايا النسبية لها"، رسالة ماجستير، جامعة المنصورة، كلية التجارة، قسم الاقتصاد، 0 أ r. 